\title{
Argument structure of classifier predicates in Russian Sign Language
}

\author{
Vadim Kimmelman ${ }^{1}$. Roland Pfau ${ }^{2}$. \\ Enoch O. Aboh ${ }^{2}$
}

Received: 10 August 2017 / Accepted: 7 March 2019 / Published online: 3 April 2019

(C) The Author(s) 2019

\begin{abstract}
We analyze classifier predicates in Russian Sign Language (RSL) using a combination of naturalistic corpus and elicited data in order to determine their argument structure, and to test the generalization, based on research on other sign languages, that there is a clear relation between argument structure and classifier type (Benedicto and Brentari 2004). We propose that whole-entity classifier predicates are intransitive unaccusative, and that body-part classifier predicates are optionally transitive. Contrary to previous research on other sign languages, we argue that handling classifier predicates in RSL describe complex events with two subevents: one of handling, and one of movement, which are not necessarily causally connected. We further suggest that the 'moving legs' classifier predicate in RSL also describes a complex event consisting of two subevents. To account for these facts, we develop a formal analysis of classifier predicates in RSL. Specifically, we argue that wholeentity and body-part classifier handshapes are agreement markers, while handling classifier handshapes as well as the 'moving legs' classifier handshape represent an argument in combination with a verbal root. This casts doubt on the observation made in the literature that classifiers straightforwardly determine the argument structure of classifier predicates, since different classifiers in RSL represent different grammatical phenomena. In addition, we show that event structures associated with some classifier predicates are more complex than those associated with monoclausal structures in spoken languages.
\end{abstract}

Keywords Argument structure $\cdot$ Sign language $\cdot$ Classifier predicates $\cdot$ Event decomposition

V. Kimmelman

vadim.kimmelman@gmail.com

1 University of Bergen, Bergen, Norway

2 University of Amsterdam, Amsterdam, Netherlands 


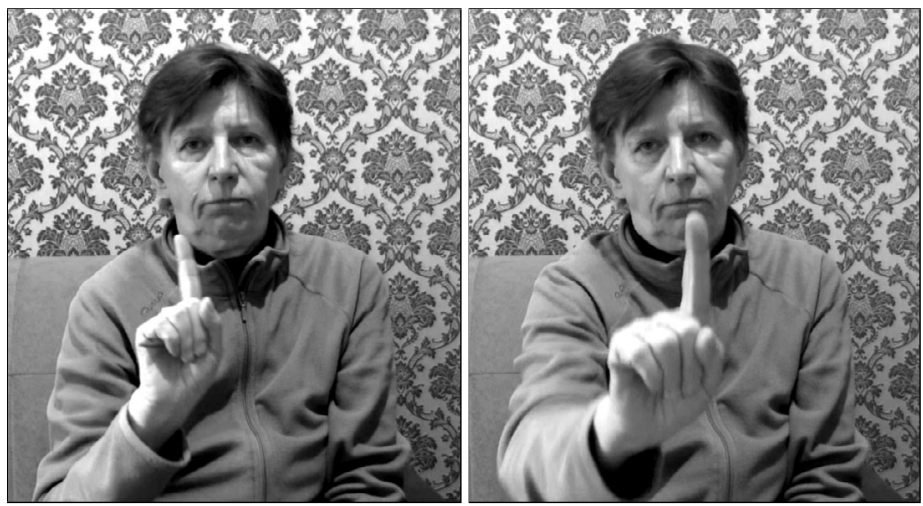

Fig. 1 Screenshots of the predicate CL(1)-MOVE.FORWARD from (1)

\section{Introduction}

Classifier predicates (CLPs) in sign languages are verbal signs in which the movement of the hand expresses the movement or location of some object, while the handshape refers to some formal or semantic properties of this object. For instance, in example (1), ${ }^{1}$ see also Fig. 1, the predicate consists of the handshape "1" (an extended index finger), which is a classifier for long thin objects, referring to the MAN, and the forward movement of the hand, referring to the movement of the man.

MAN CL $L_{W E}(1)$-MOVE.FORWARD

'The man moves forward.'

This phenomenon has received a lot of attention within the field of sign language linguistics. Some researchers cast doubt on the idea that these signs are similar in properties to verbs with verbal classifiers in spoken languages, and argue that they are to a large extent gestural, rather than grammatical, elements embedded in a signed language (Cogill-Koez 2000; Schembri 2003). Others (starting probably with Supalla 1982) suggest linguistic analyses of these constructions, where the handshape is analyzed as a classifier morpheme that combines with a verbal root expressing movement or location (Zwitserlood 2012), although some interface with the gestural component is still required to explain the iconic nature of this construction.

In this paper, we discuss the results of the first research on argument structure of classifier predicates in Russian Sign Language (RSL). We use a combination of naturalistic corpus data and several elicitation techniques. Our investigation shows that the relation between classifier type and argument structure in RSL is more intricate than one would assume based on previous studies. We propose a new formal account of CLPs in RSL using the event decomposition approach by Ramchand (2008a) as

\footnotetext{
${ }^{1}$ All examples come from Russian Sign Language, unless specified otherwise. Signs are glossed in SMALL CAPS; CL stands for classifier. For the sake of space, nonmanual markers are omitted in all examples. See further the annotation conventions at the end of the paper.
} 
a theoretical framework. In addition, we find that event structures associated with some classifier predicates in RSL are more complex than possible monoclausal event structures in Ramchand's (2008a) framework.

\section{Classifier predicates in sign languages}

\subsection{Basic properties}

Classifier predicates are predicates of movement or location (Zwitserlood 2012). These signs have a complex morphological structure: they involve movement of the arm that expresses movement of the referent; ${ }^{2}$ if the sign moves from one location to another, these locations refer to the Source and Goal of the movement that is being described. The handshape (the classifier) refers to some semantic properties of the moving object described by the predicate.

The handshapes are analyzed as classifiers, and the predicates as classifier predicates, due to their resemblance to verbal/predicate classifier affixes in spoken languages. Consider, for instance, the example from Gunwinggu in (2), in which the subject 'water' is referenced by the verbal prefix for liquid objects, while the verb describes its movement.

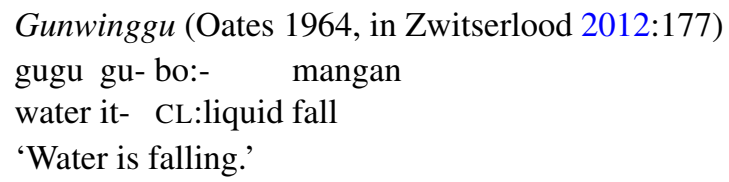

Classifier predicates in sign languages are usually iconic: the movement in the sign depicts the shape and the speed of the movement of the referent described by the predicate. For instance, in (1) and Fig. 1 above, the predicate contains forward movement to depict the forward movement of the man. This movement can be changed to follow a complex trajectory in space to depict a complex trajectory of real-life movement of the man. The signer can modulate the speed of the sign to reflect changes in real-life speed of the movement being described. Furthermore, the starting and ending locations of the movement of the sign usually reflect the real-world spatial arrangement of the Source and Goal. Emmorey and Herzig (2003) have shown that signers of American Sign Language (ASL) perceive locations used in spatial descriptions in an analogue manner.

Classifier handshapes are also highly iconic, but, unlike the shape and speed of the movement, and the exact points in space used for locations, handshapes are restricted and categorical (but see further discussion of handling handshapes below). For instance, the "1" handshape in (1) can refer to long and thin objects in RSL, and the "1-l" handshape with the extended index and little fingers refers to cars, planes (Fig. 2), and square objects.

\footnotetext{
${ }^{2} \mathrm{~A}$ small downward movement is used to express location of a referent that does not move.
} 

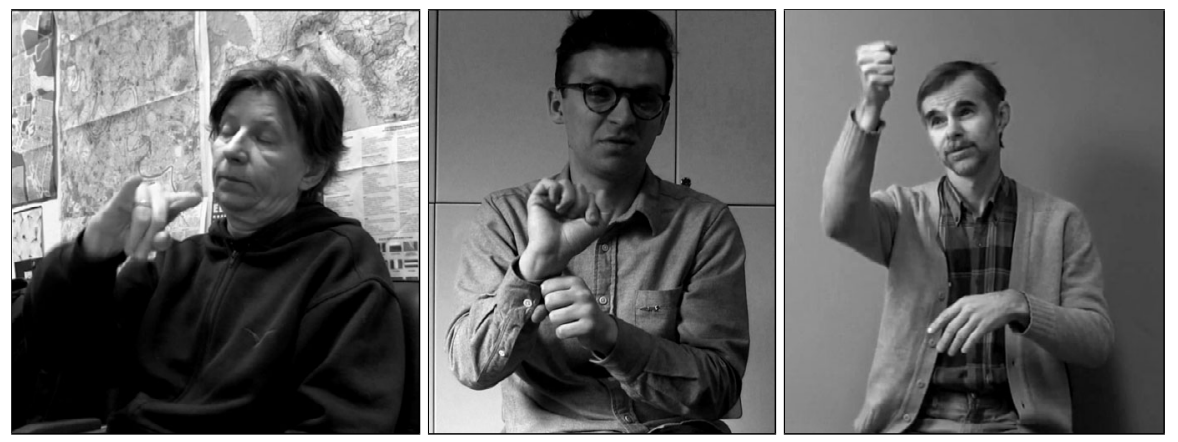

Fig. 2 From left to right: semantic classifier handshape for a plane; body-part classifier handshape for a head; handling classifier for a thin object in RSL

There are different types of classifiers (as well as different classifications, see Zwitserlood 2012 for further discussion). Most importantly, the following types are distinguished:

1. Whole-entity classifiers, which refer to whole objects whose movement or location is described by the predicate. They can be further divided into:

- Semantic classifiers, which refer to a semantic class of objects (humans, trees, cars). See the left picture in Fig. 2.

- Size-and-shape specifiers, which refer to some formal characteristics of the contour of objects (thin objects, round objects, etc.). ${ }^{3}$

2. Body-part classifiers, where the hand refers to a body part: a hand, a head, a leg, a tail, etc. See the center picture in Fig. 2.

3. Handling classifiers, where the hand refers to a hand or another manipulator handling some object. See the right picture in Fig. 2.

Semantic and body-part classifier handshapes are clearly categorical: a sign language usually has a small set of handshapes that can be used as classifiers of these types. There is also cross-linguistic variation: for instance, the classifier for cars in RSL uses the same shape as the plane classifier in Fig. 2, while in ASL another handshape is used with the thumb, index finger, and middle finger extended. However, for size-and-shape specifiers and handling classifier handshapes, it is more difficult to claim that they are categorical. Consider the handling classifier for handling a thin object depicted in Fig. 2. In principle, various degrees of thickness of the object can be depicted by various degrees of openness of the hand.

Emmorey and Herzig (2003) show that ASL signers in both production and perception of some size-and-shape specifiers show categorical, and not gradual patterns. On the other hand, Sehyr and Cormier (2015) in their experimental investigation of perception of handling handshapes in British Sign Language find a more subtle pattern reflecting graded category organization. More research is needed to understand how signers behave.

\footnotetext{
${ }^{3}$ Here, we only mean static size-and-shape specifiers, because tracing specifiers do not belong to the system of classifier predicates, as convincingly argued e.g. by Zwitserlood (2012).
} 
For our research the role of iconicity in the development of classifier predicates, and the extent to which they show gradual vs. categorical effects in production and perception are not directly relevant. Recently, it has been demonstrated that formal linguistic analyses are applicable to even highly iconic phenomena in sign languages (Schlenker 2014; Davidson 2015; Oomen 2017). In this paper, we focus on the clearly linguistic parts of CLPs (their event and argument structures), and we return to the issue of iconicity in Sect. 6.3.

\subsection{Argument structure}

Several researchers working on various sign languages have noticed that there is a strong connection between classifier type and transitivity of the CLP. One of the first to observe this relationship was Kegl (1990). She demonstrated that verbs like BREAK in ASL can be intransitive if a whole-entity classifier is used (3a), and transitive if a handling classifier is used (3b).
ASL (adapted from Kegl 1990:156-157)
a. STICK CL $L_{W E}(1)-B R E A K$
'The stick broke by itself.'
b. STICK, M-A-R-I-S-A CL $L_{\mathrm{HL}}$ (SS)-BREAK
'Marisa broke the stick.'

Benedicto and Brentari (2004) in their research on CLPs in ASL confirm this observation, and argue further that whole-entity CLPs are intransitive unaccusative, body-part CLPs are intransitive unergative, and handling CLPs are transitive. They employ a number of tests targeting external and internal arguments to show that the only argument of whole-entity CLPs is internal, the only argument of body-part CLPs is external, and that handling CLPs have both an external and an internal argument.

For instance, they used the fact discovered by Wood (1999) that, in ASL, the negative marker NOTHING can only scope over the internal argument, as demonstrated by example (4) for non-classifier verbs: NOTHING can scope over the argument of the unaccusative MELT, but not over the argument of the unergative LAUGH. When the same test is applied to CLPs, it turns out that NOTHING can scope over the only argument of a whole-entity CLP, but not over the only argument of a body-part CLP (5).
ASL (Benedicto and Brentari 2004:759)

a. BUTTER MELT NOTHING

'None of the butter melted.'

b. *WOMAN LAUGH NOTHING

'\#No woman laughed.'

(5) ASL (Benedicto and Brentari 2004:760)
a. ACTOR $\mathrm{CL}_{\mathrm{WE}}(1)$-BOW NOTHING
'None of the actors bowed.'
b. ACTOR $\mathrm{CL}_{\mathrm{BP}}(\mathrm{S})$-BOW NOTHING
'\#None of the actors bowed.' 
As for the external argument, Benedicto and Brentari (2004) show that, with nonclassifier predicates, the agent-oriented adverb WILLING can only be used when there is an external argument. Similarly, it can be used with body-part and handling CLPs, but not with whole-entity CLPs.

Importantly, similar observations, namely that whole-entity CLPs are intransitive, and handling CLPs are transitive, have been made for other sign languages. Glück and Pfau (1998) have observed it for German Sign Language (DGS), Zwitserlood (2003) for Sign Language of the Netherlands (NGT); ${ }^{4}$ Benedicto et al. (2007) for Argentinian and Catalan Sign Languages, and Pavlič (2016) for Slovenian Sign Language.

\subsection{Formal approaches}

Benedicto and Brentari (2004) develop a syntactic approach to account for the relation between classifier type and argument structure of CLPs in ASL. They propose that a CLP's verbal root (which can be MOVE or BE depending on whether movement or location is described) always selects one argument, but does not assign it a thematic role, while classifiers of different types introduce different functional heads, and the argument can move to a specifier of these heads to be interpreted as external or internal.

(6) 'The man moves.'

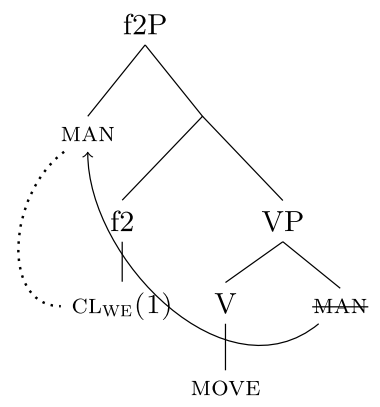

(7) 'The man moves his head.'

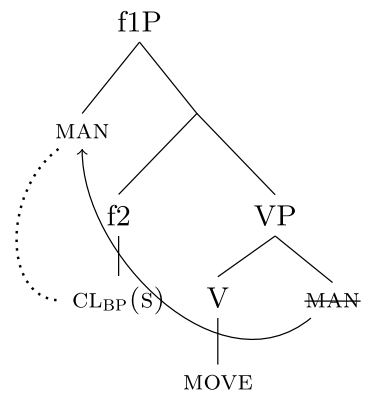

${ }^{4}$ See, however, de Lint (2018) on a recent account of classifier predicates in NGT arguing against some of the generalizations above. 


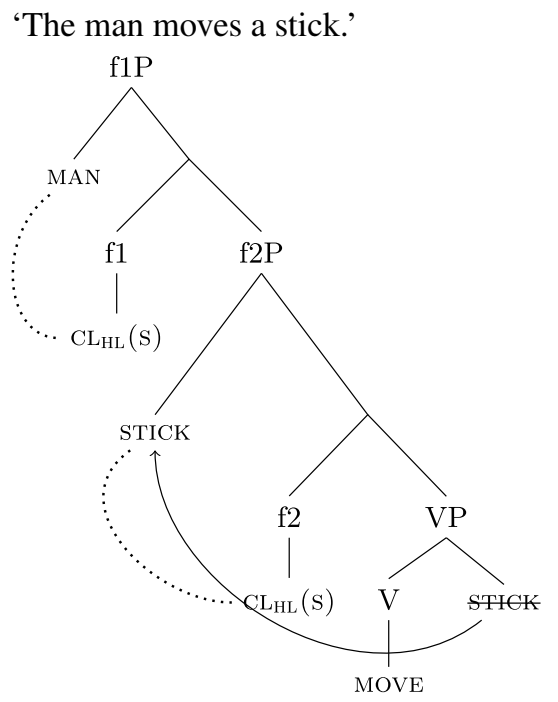

Specifically, a whole-entity classifier manifests an $\mathrm{f} 2$ functional head that hosts internal arguments in its specifier (6), ${ }^{5}$ and a body-part classifier displays an f1 functional head that hosts external arguments (7). Handling classifiers are complex morphemes introducing both the $\mathrm{f} 1$ and $\mathrm{f} 2$ heads; the argument selected by the verbal root moves to the specifier of the $\mathrm{f} 2$ projection, and another argument is introduced in the specifier of $\mathrm{f1}(8)$.

Once an argument has moved to the specifier position of a projection introduced by an $\mathrm{f} 1$ or and $\mathrm{f} 2$ head, Spec-Head agreement (depicted by the dotted line) determines the choice of the right classifier. This accounts for the fact that the choice of a classifier is dependent on the class or shape of the moving object.

Note that this account of CLPs in ASL views argument structure as a part of syntax: although the verbal root selects one argument, it does not assign any thematic role to it. Thematic roles are assigned later in the derivation when the argument lands in the specifier of a particular projection (f1 or f2). Benedicto and Brentari (2004) acknowledge that it is also possible to formulate a lexical account for these phenomena in which the classifier morpheme is attached to a verbal root and determines its argument structure in the lexicon; however, they do not pursue this idea further. Irrespective of the precise formulation, what the ASL data show is a clear relation between argument structure and classifier type, a relation that has to be modeled within any framework.

Benedicto and Brentari (2004) also note an important property of the f1 projection in ASL: the argument that lands in its specifier is interpreted as an Agent, not as a Cause. For instance, it is not possible to have an instrument or a non-human cause as a subject of a handling CLP. In this respect, the CL predicate $\mathrm{CL}_{\mathrm{HL}}$ (SS)-BREAK in ASL is different from the English verb break, as the latter can take instruments and causes as subjects (e.g. The stone broke the glass.).

\footnotetext{
${ }^{5}$ This and the following examples are simplified representations of the proposal in Benedicto and Brentari (2004).
} 
Grose et al. (2007) argue that Benedicto and Brentari's analysis for body-part CLPs has to be modified. Specifically, they argue that body-part CLPs have an internal argument as evidenced by the fact that they can express telic events. For instance, (9a) is an atelic use of the body-part CLP for the head, while (9b) is a telic use of the same predicate.

ASL (Grose et al. 2007:1259)
a. $\mathrm{CL}_{\mathrm{BP}}(\mathrm{S})$-SHAKE
'She shook her head.'
b. $\mathrm{CL}_{\mathrm{BP}}(\mathrm{S})$-BOW
'She bowed her head.'

In Benedicto and Brentari's analysis, body-part CLPs only have an external argument. However, according to Grose et al. (2007), telicity can only be achieved if the predicate has a delimited internal argument, so (9b) should be impossible. Grose et al. (2007) further argue that the tests which Benedicto and Brentari (2004) used to identify the presence of internal arguments in CLPs do not demonstrate clearly that body-part CLPs lack an internal argument. Even though the observation that telic predicates must have an internal argument is debatable (Ramchand 2008a), an important insight in the analysis by Grose et al. (2007) is that body-part CLPs involve an internal argument which, however, need not be overtly expressed. As we will show, in RSL, body-part CLPs are in fact overtly transitive. ${ }^{6}$

Zwitserlood (2003) develops a different formal analysis for similar phenomena in NGT. Her analysis is couched in the Distributed Morphology framework, and its purpose is to account for all types of agreement phenomena in NGT. We will not discuss the details of her analysis because it goes beyond the focus of this paper (see also van Gijn and Zwitserlood 2006). Most importantly, for Zwitserlood, the verbal root selects one obligatory internal argument, the Theme, ${ }^{7}$ and the classifier itself is a spell-out of the agreement marker agreeing with the Theme argument. Handling classifiers appear when there is a voice node responsible for the introduction of the external argument. Therefore, in Zwitserlood's analysis, classifiers do not determine the argument structure of CLPs, but they are reflections (spell-out of agreement) of different argument structures.

In this paper, we take the account of Benedicto and Brentari (2004) as a starting point in our investigation of CLPs in RSL because this account contains a clear explanation for the observation that argument structure of CLPs is dependent on the classifier type, and makes clear predictions, also for other signed languages that have similar classifier types. Moreover, this approach has already been extended to several other sign languages (Benedicto et al. 2007; Pavlič 2016).

\footnotetext{
${ }^{6}$ Grose (2008) also developed a general analysis of event and argument structures for ASL in terms somewhat similar to the ones we are going to use in Sect. 5. We do not discuss his proposal in detail, focussing instead on comparing empirical claims about ASL to our findings for RSL, and on assessing Benedicto and Brentari (2004) against RSL data.
}

${ }^{7}$ It also optionally selects one or two external arguments, the Goal and the Source. 
We want to answer the following research questions:

1. Is there a clear relation between classifier type and argument structure of CLPs in RSL?

2. If so, can this relation be accounted for by the model proposed by Benedicto and Brentari (2004)?

\section{Methodology}

\subsection{Russian Sign Language}

Russian Sign Language (RSL) is a language used by deaf and hard-of-hearing people in Russia. According to the latest census organized in 2010, it is used by 120,000 people. $^{8}$

Previous research on RSL has been devoted to various topics in morphology, syntax, semantics and pragmatics. However, classifier predicates in RSL have not been described before.

In order to investigate the properties of argument structure of CLPs in RSL, we combined an analysis of corpus data with controlled elicitation and grammaticality judgement tasks.

\subsection{Corpus data}

In order to investigate the relation between classifier type and argument structure, we looked for examples of classifier predicates in the corpus of RSL (Burkova 2012-2015). The corpus currently contains data from 37 signers, mainly from two regions (Moscow and Novosibirsk). The total number of signs in the corpus, assessed based on the number of glosses on the tier for the right hand, is around 25,000. The corpus has been provided with individual glosses for signs (on separate tiers for the two hands) and with free sentence-level translation.

Classifier predicates are not consistently annotated in the corpus; therefore, no automatic analysis of such predicates is possible. We looked for examples of classifier predicates by searching for glosses that describe motion and location, such as WALK, MOVE, RUN, and also by browsing through texts of one particular type, namely retellings of the Canary Row cartoon ${ }^{9}$ which are available for 13 signers from Moscow. For the found examples, we identified whether the classifier type (wholeentity, body-part, handling) is predictive of the argument structure of the predicate as described in the previous section.

This method of data collection allowed us to draw the following conclusions:

1. Whole-entity classifiers are often used in intransitive predicates;

\footnotetext{
${ }^{8}$ See the preliminary results of the census reported here: http://www.rg.ru/2011/12/16/stat.html (accessed 12 March 2019).

${ }^{9}$ Retelling of this cartoon has been used to investigate classifier predicates and spatial language in general in many previous studies of sign languages and co-speech gesture.
} 


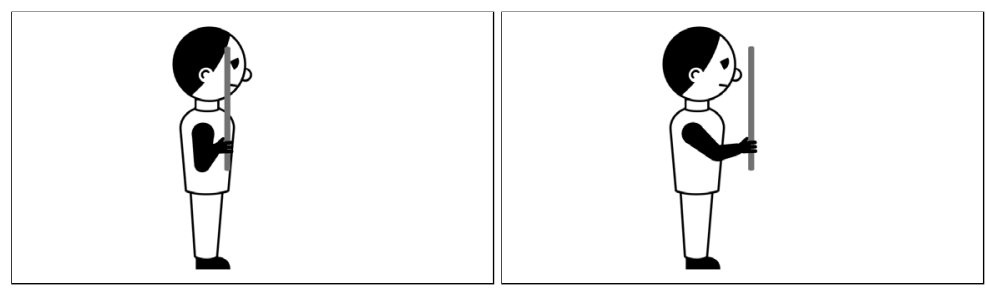

Fig. 3 Screenshots from the video of a man holding and moving a stick forward

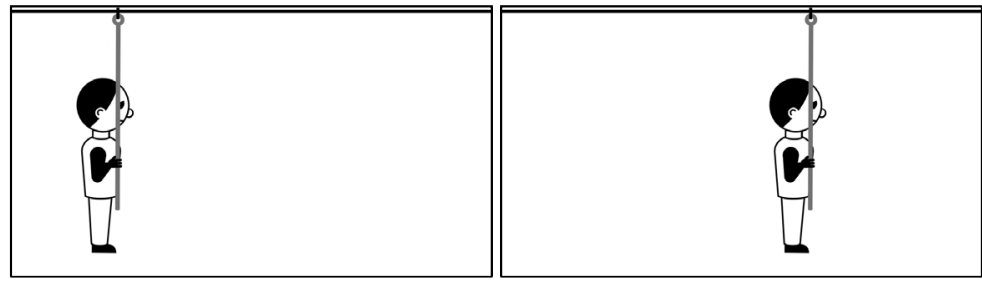

Fig. 4 Screenshots from the video of a man moving because he holds on to a stick

2. Handling classifiers are often used in transitive predicates;

3. Patterns (i) and (ii) are not without exception.

In the remainder of the paper, when we use examples from the corpus, we provide a direct link to the example in the online version of the corpus. Interested readers will have to register in order to access the examples.

\subsection{Elicitation}

One important exception to the expected argument structure pattern was the case of handling classifier predicates. We found that the same classifier predicate can describe different situations: (i) an Agent moves a Patient, (ii) an Agent holds to the Patient and moves because the Patient moves, and (iii) an Agent holds a Patient, and the Agent moves (independently). We will discuss these (and other) meanings in detail in Sect. 4.3. The problem with corpus data is that it is impossible to find minimal pairs, that is, exactly the same classifier predicate which has different meanings in different contexts. Therefore, we turned to elicitation.

We designed short animations which described situations which were different exactly in the relevant respects. ${ }^{10}$ For instance, in order to study the handling classifier $\mathrm{CL}_{\mathrm{HL}}(\mathrm{S})$, we created the following animations:

1. A man is moving a stick forward (Fig. 3).

2. A man is holding on to a stick which moves, so the man also moves (Fig. 4).

3. A man is moving (because he stands on a moving platform), while holding a stick (which has nothing to do with movement) (Fig. 5).

${ }^{10}$ Animations were created by A. Rysaeva. We thank her for her kind collaboration. 


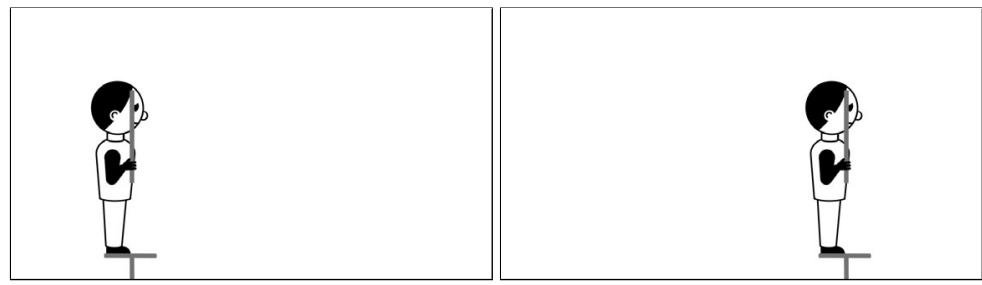

Fig. 5 Screenshots from the video of a man moving while holding a stick

We created such triplets of animations with different object types (a stick, a balloon, a ball), and with different movement types (a straight movement forward or upward, or an arc-shaped movement). For one type of object (a stick), we also created a complex movement shape (upward-forward zigzag) in order to test whether the classifier predicate is fully productive in all three contexts. In total, there were 21 animations (7 different objects/trajectories $* 3$ types of handling).

We elicited descriptions of these videos from 10 native signers in Moscow. The signers were instructed to describe the videos as briefly as possible. No explicit instructions about using classifier predicates (or any other means of description) were given. The videos were presented in a pseudo-random order such that two videos of the same object were never adjacent. In addition, after describing video-clips, the signers were asked to provide judgements concerning possible modifications of the constructions that they produced.

Finally, in order to confirm our findings and further investigate the properties of some CLPs, we conducted a grammaticality judgement task with 16 signers in Moscow.

\section{Descriptive results}

In this section, we describe our findings concerning argument structure of different types of classifier predicates: whole-entity CLPs (Sect. 4.1), body-part CLPs (Sect. 4.2), and handling CLPs (Sect. 4.3). We also discuss what problems these data present for an analysis following Benedicto and Brentari (2004), but our own analysis is postponed until Sect. 5 .

\subsection{Whole-entity CLPs}

RSL has a variety of whole-entity classifiers. For instance, the " 1 " handshape is used to refer to long objects (including humans); the "1-1" handshape oriented sideways is used to refer to cars, while with the palm oriented down, it is used to refer to planes; the " $5 b$ " (all fingers slightly bent) handshape is used to refer to round objects, etc.

In general, whole-entity classifiers are indeed used to form intransitive predicates which describe the movement of the only argument in the sentence (10a). The movement can be uncontrolled by the theme; it can be caused by external forces. However, it can also be controlled - the subject can move deliberately, as in example (10b), 
where a whole-entity classifier predicate $\mathrm{CL}_{\mathrm{WE}}(3)$-MOVE and a non-classifier predicate WALK describe the same situation of walking. We suggest that whole-entity CLPs are indeed unaccusative intransitive predicates, and that (lack of) control of the movement is deduced from context. The RSL data is thus compatible with the analysis suggested by Benedicto and Brentari (2004) and Zwitserlood (2003).

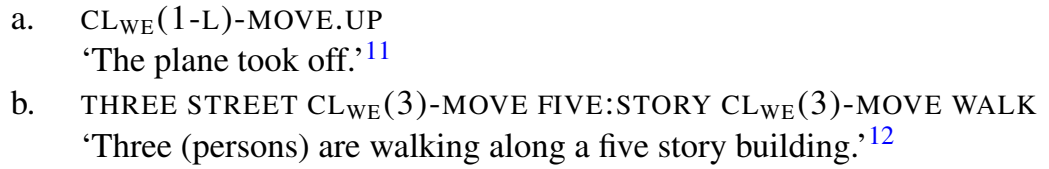

b. THREE STREET CL $L_{W E}(3)$-MOVE FIVE:STORY $\mathrm{CL}_{\mathrm{WE}}(3)$-MOVE WALK 'Three (persons) are walking along a five story building.' 12

However, whole-entity classifiers also occur in other contexts. One systematic exception to the intransitive use of whole-entity CLPs concerns classifiers for vehicles, such as planes, cars, and buses. This type of classifiers can also occur in a clause where the subject is not the vehicle, but the driver/pilot or a passenger. Consider example (11): the context is that even if you are deaf or blind, you can still travel by plane by yourself (the meaning of SELF.INTENS is 'by yourself'). The classifier $\mathrm{CL}_{\mathrm{WE}}(1-\mathrm{L})^{13}$ still refers to the plane, but the subject is not the plane, it is the passenger, as is clear from the context.

\section{SELF.INTENS CL $L_{W E}(1-L)$-MOVE.BACK.AND.FORTH SELF.INTENS CAN} 'One can fly around by oneself.' 14

A possible analysis is that the classifier predicate $\mathrm{CL}_{\mathrm{WE}}(1-\mathrm{L})$-MOVE, and other vehicle CLPs used transitively, have lexicalized and should be glossed as GO.BY.PLANE, DRIVE, etc., and that is why its argument structure is different from whole-entity CLPs. Similar facts have also been observed for ASL and NGT, and the researchers have also suggested a lexicalization account (Benedicto and Brentari 2004; Zwitser$\operatorname{lood} 2003,2012)$. However, it is also possible to analyze such cases without reference to lexicalization, as in our proposal whole-entity classifiers do not determine the argument structure of the predicate. We develop a formal analysis for whole-entity CLPs in Sect. 5.2.

\subsection{Body-part CLPs}

RSL has body-part classifiers. In particular, the hand can represent the hand $\left(\mathrm{CL}_{\mathrm{BP}}(5)\right)$, extended index fingers on the two hands can represent the legs $\left(\mathrm{CL}_{\mathrm{BP}}(11)\right)$, and the fist can represent the head $\left(\mathrm{CL}_{\mathrm{BP}}(\mathrm{S})\right)$.

As for the argument structure, body-part classifier predicates can be transitive in RSL, as (12a) shows, where the classifier predicate $\mathrm{CL}_{\mathrm{BP}}(\mathrm{S})$-MOVE.DOWN 'nod' is

\footnotetext{
${ }^{11}$ Video available at http://rsl.nstu.ru/data/view/id/198/t/871901/d/874614.

${ }^{12}$ Video available at http://rsl.nstu.ru/data/view/id/31/t/40300/d/45300.

${ }^{13}$ See glossing conventions at the end of the paper for the description of all handshapes mentioned in the text.

${ }^{14}$ Video available at http://rsl.nstu.ru/data/view/id/198/t/915760/d/918184.
} 
accompanied by an overt object IX-A(HEAD) - a pointing sign to the head. It is also possible to use this CLP intransitively, with the body-part being the only argument (12b). Of course, it is also possible to omit the body-part argument but to have the body-part owner as an argument in the sentence (12c).
a. IX-1 IX-A(HEAD) $\mathrm{CL}_{\mathrm{BP}}(\mathrm{S})$-MOVE.DOWN
'I am nodding my head.' ${ }^{\text {' }}$
b. MY HEAD $\mathrm{CL}_{\mathrm{BP}}(\mathrm{S})$-MOVE.BACK
'My head moved back.'
c. IX-1 $\mathrm{CL}_{\mathrm{BP}}(\mathrm{S})$-MOVE.DOWN
'I am nodding.'

Importantly, the possessor of the body-part does not have to be an Agent, as example (13) shows. The subject here is IX-1, as can be seen from the personal (not possessive) form of the pronoun (compare to (12b) which has the possessive pronoun MY), but it has no control over the movement of the head.

$$
\begin{aligned}
& \text { IX-1 IX-A(HEAD) } \mathrm{CL}_{\mathrm{BP}}(\mathrm{S}) \text {-SHAKE } \\
& \text { 'My head is shaking.' }
\end{aligned}
$$

The fact that body-part CLPs in RSL can be used transitively is not directly compatible with the analysis in Benedicto and Brentari (2004), because their structure for such predicates has only one position in which an argument can be assigned a thematic role (see (7)). It should be possible to apply the analysis developed by Grose et al. (2007) to the RSL data. However, the more serious problem for both types of analyses developed for ASL lies in the fact that the subjects of the body-part CLPs in RSL are not necessarily Agents. Regardless of the position of the object in these analyses, the subject is predicted to have the agentive interpretation. We will therefore discuss this classifier type further in Sect. 5.3.

Additionally in RSL, as in ASL (Benedicto and Brentari 2004:794), the classifier with the $2 b$ handshape referring to legs can be used in two different ways. The signer may move the fingers (in addition to the movement of the whole hand) (14a), or not move the fingers (14b). ${ }^{16}$ The latter case usually indicates that the subject is a Theme, and thus the classifier could be analyzed as a whole-entity classifier, not a body-part classifier, although its shape reflects the body part. In order to distinguish between the two cases, we will gloss the "moving legs" classifiers $\mathrm{CL}_{\mathrm{ML}}(2 \mathrm{~B}-\mathrm{MOVE} 2)$-MOVE, as in (14a), to show that two movements are simultaneously present.

$$
\begin{aligned}
& \text { a. } \mathrm{CL}_{\mathrm{ML}}(2 \mathrm{~B}-\mathrm{MOVE} \text { )-MOVE.UP } \\
& \text { 'I am walking up.' } 17 \\
& \text { b. H1: } C L_{\mathrm{WE}}(2 \mathrm{~B}) \text {-MOVE.FORWARD } \\
& \text { H2: } C L_{\mathrm{WE}}(\mathrm{B}) \text {-MOVE.FORWARD } \\
& \text { 'A man is moving forward on a moving platform.' }
\end{aligned}
$$

\footnotetext{
${ }^{15}$ Video available at http://rsl.nstu.ru/data/view/id/198/t/237242/d/238222.

${ }^{16} \mathrm{H} 1$ and $\mathrm{H} 2$ stand for the two hands which simultaneously perform different signs.

${ }^{17}$ Video available at http://rsl.nstu.ru/data/view/id/21/t/41040/d/42610.
} 

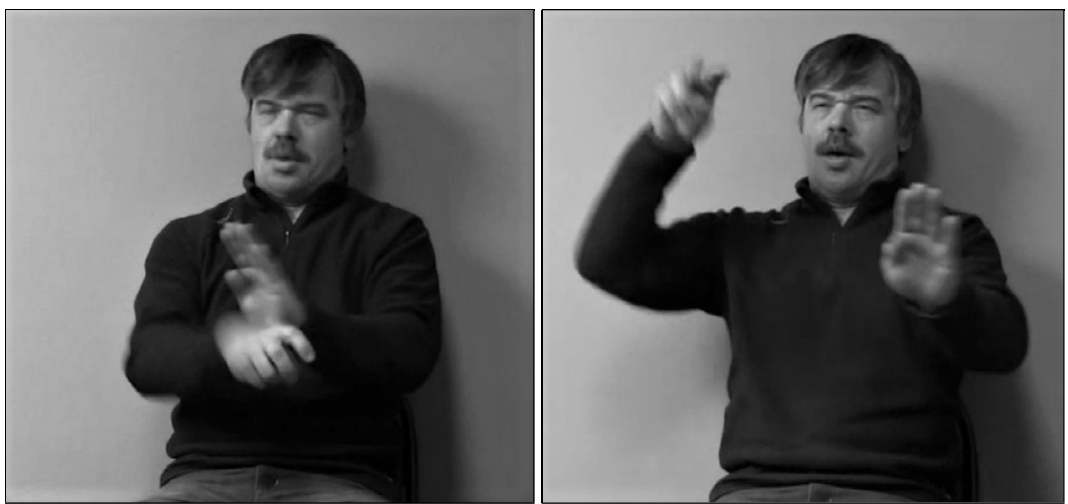

Fig. 6 Screenshots of the $\mathrm{CL}_{M L}(2 \mathrm{~B}-\mathrm{MOVE} 2)$-MOVE from example (17)

Although Benedicto and Brentari (2004) made the same observation, they did not discuss the fact that in examples like (14a) the classifier is not just the handshape, but rather a combination of the handshape and hand-internal movement, which then combines with another movement, namely the path movement of the hand.

It is dubious that the 'moving legs' classifier should be analyzed as a body-part classifier (and thus we use the 'ML', rather than the 'BP' subscript to refer to it). Firstly, the argument that the classifier refers to (the legs) can never be overt (15), unlike the body-part arguments of other body-part classifiers (13).

$$
\begin{aligned}
& \text { *IX-1 LEGS } \mathrm{CL}_{\mathrm{ML}} \text { (2B-MOVE2)-MOVE } \\
& \text { Intended meaning: 'I move my legs.' }
\end{aligned}
$$

More importantly, it turns out that it would be wrong to translate the $\mathrm{CL}_{\mathrm{ML}}(2 \mathrm{~B}$ MOVE2)-MOVE CLP as 'to walk'. The movement of the legs and the movement of the person are events with different properties and different argument structures, and they are not necessarily causally connected. Specifically, the movement of the legs has to be controlled: it is not possible to use this CLP to describe shaking legs (16a) (a true body-part classifier for legs with the " 1 " handshape should be used instead (16b)). In contrast, the movement of the person does not have to be controlled, as example (17) (see also Fig. 6) demonstrates: the cat that is the subject of the CLP is falling (thus moves uncontrollably) while simultaneously moving its legs. This example also shows that the movement of the legs and the movement of the person do not have to be causally connected, because, in the event described in this example, neither of the movements causes the other movement.

$$
\begin{aligned}
& \text { a. *IX-1 } \mathrm{CL}_{\mathrm{ML}}(2 \mathrm{~B}-\mathrm{SHAKE}) \text {-MOVE } \\
& \text { Intended meaning: 'My leg is shaking.' } \\
& \text { b. IX-1 } \mathrm{CL}_{\mathrm{BP}}(1)-\mathrm{SHAKE} \\
& \text { 'My leg is shaking.' }
\end{aligned}
$$




$$
\mathrm{CL}_{\mathrm{ML}}(2 \mathrm{~B}-\mathrm{MOVE} 2)-\mathrm{MOVE}
$$

'(The cat) flies through the air wiggling its legs.' 18

Finally, it is even possible to use the 'moving legs' CLP without any movement of the hand through space. This CLP can be used to describe, for instance, a person walking on a treadmill (18).

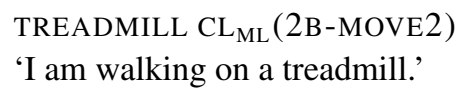

It is clear that the structure in (7) by Benedicto and Brentari (2004) is not compatible with the complex meaning of the 'moving legs' CLP. We will therefore develop a different analysis for it in Sect. 5.4.

\subsection{Handling CLPs}

\subsubsection{Initial investigation}

RSL commonly uses handling CLPs, where the handshape depends on the shape of the object that is being held by some animate participant. For instance, the " $\mathrm{S}$ " shape is used to describe holding thin objects, like sticks, and the " $F$ " handshape (index finger and thumb form a circle) is used to describe holding a small object, like a pin, or a round object, like a coin. Quite often, the handling CLP is used, as expected, to describe an Agent moving a Theme. The hand represents the hand of the Agent, and its shape is dependent on the shape of the Theme. Such use of a handling classifier is illustrated in (19), where the two hands represent the hands of the Agent who moves the Theme (the ball).

\section{BALL HEAVY CL $\mathrm{WE}_{\mathrm{W}}(5 \mathrm{~B} 5 \mathrm{~B})$-MOVE}

'[The canary] is carrying the heavy ball.' 19

However, we also observed some facts that are problematic if we want to apply the analysis from Benedicto and Brentari (2004) to our data. The first problem is that, in RSL, the meaning of a handling CLP necessarily involves the hand. Consider the following scenario: I shout at the dog sitting on the table, and the dog jumps down from it. It is impossible to use the handling CLP $\mathrm{CL}_{\mathrm{HL}}$ (55)-MOVE.DOWN to describe this event: see (20) and Fig. 7.

\section{IX-1 DOG TABLE CL $\mathrm{HL}_{\mathrm{H}}$ (CC)-MOVE.DOWN}

'I move the dog down from the table (by my hands, not by shouting).'

However, in Benedicto and Brentari's analysis, handling CLPs receive the following interpretation based on their syntactic analysis in (8): the Agent causes the Theme to

\footnotetext{
${ }^{18}$ Video available at http://rsl.nstu.ru/data/view/id/311/t/41250/d/42500.

${ }^{19}$ Video available at http://rsl.nstu.ru/data/view/id/243/t/18310/d/19870.
} 


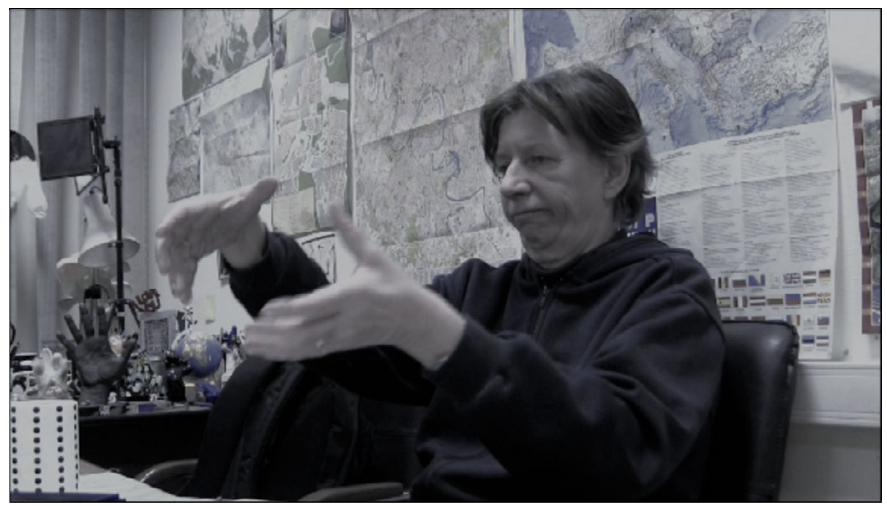

Fig. 7 Screenshot of the $\mathrm{CL}_{\mathrm{HL}}(\mathrm{CC})$-MOVE.DOWN from example (20)

move. If this was the case for RSL, a possible meaning of (20) should be 'I cause the dog to move down.' But this is not the meaning of (20), according to the native signers. The fact that the movement of the Theme should be directly caused by the hands of the Agent is a part of the meaning. We develop an account for this fact in Sect. 5.5.

The second problem is that sometimes the handling CLP does not contain any movement of the hand, as in (21a). Note that this is different from a handling CLP with the BE verbal root (21b) in two respects: firstly, the BE verbal root in fact contains a small downward movement (Supalla 1982), and secondly, it can be modified for location to express where the Agent is causing the Theme to be located, unlike (21a). Thus we conclude that (21a) does not contain the root BE.
a. MAN STICK $\mathrm{CL}_{\mathrm{HL}}(\mathrm{S})$
'The man holds a stick.'
b. MAN STICK $\mathrm{CL}_{\mathrm{WE}}(\mathrm{S})-\mathrm{BE}-\mathrm{A}$
'The man causes a stick to be there (at location A).'

Turning to the third problem, as we have already hinted upon in Sect. 3, one of our main findings is that handling classifiers occur in a wider range of contexts than what the analyses in Benedicto and Brentari (2004) or Zwitserlood (2003) would predict. ${ }^{20}$ First, as mentioned above, handling CLPs can indeed be used to describe a situation where an Agent moves a Theme (from now on, the "regular handling" context: RH, as in (19)). In addition, handling classifiers are used to describe a situation in which someone moves because of holding on to some object (recall Fig. 4). For instance, example (22) describes a situation from the Canary Row cartoon in which the cat swings on a rope from one building to the other. From now on, we will call this the "moving because handling" context: $\mathrm{MBH}$.

\footnotetext{
${ }^{20}$ Note, however, that Zwitserlood excludes these non-standard usages of handling classifiers by definition, so her analysis is not supposed to account for them, as she considers such uses different from the "regular" use of handling classifiers.
} 
ROPE $\mathrm{CL}_{\mathrm{HL}}$ (SS)-MOVE.FORWARD

'[The cat] swings on the rope.' $\mathrm{MBH}^{21}$

The third type of situation is when someone moves while holding something in their hand, so the movement and the holding events are not causally connected but just simultaneous (recall Fig. 5). Consider example (23) (also depicted in the right frame of Fig. 2), where the cat has catapulted itself to grab the canary, and then, having grabbed it, falls down. The CLP $\mathrm{CL}_{\mathrm{HL}}(\mathrm{S})$-MOVE.DOWN has the handling classifier which describes the cat holding the canary while the movement in this predicate describes the movement of the cat. We will call this the "moving while handling" context: MWH.

$\mathrm{CL}_{\mathrm{HL}}(\mathrm{S})$-MOVE.DOWN

'[The cat] falls while holding [the canary].' MWH

\subsubsection{Elicitation results}

As discussed in Sect. 3, corpus data has the advantage of being naturalistic and providing us with unexpected usages of classifiers, but it does not often contain minimal pairs (triplets) with exactly the same classifier used in minimally different contexts. Thus we elicited such contexts with the help of short animated clips.

As discussed above, 10 signers of RSL participated, and each had to describe 21 situations (7 different objects/trajectories * 3 types of handling). It turns out that (i) not surprisingly, all signers use handling classifiers in the RH contexts; (ii) all signers used handling classifiers in at least one of the $\mathrm{MBH}$ contexts; (iii) five of the signers also used handling classifiers in some MWH contexts; (iv) handling classifiers can also be used in the $\mathrm{MWH}$ and $\mathrm{MBH}$ contexts with complex trajectories. Note also that the difference between $\mathrm{MBH}$ and $\mathrm{MWH}$ contexts might be less important than it seems: the signers who never used handling classifiers in MWH contexts also rarely used them in the $\mathrm{MBH}$ contexts. All together, 39 out of 70 possible $\mathrm{MBH}$ descriptions contained an appropriate handling CLP, and 27 out of 70 possible MWH descriptions contained an appropriate handling CLP. It is difficult to interpret these numbers in general, because it is clear that the MWH and MBH contexts can be described without the classifier construction that we are interested in, so the proportion of cases in which such a construction was used is not informative. What is informative is that handling CLPs clearly are compatible with the MBH and MWH contexts for native signers.

Based on elicited data, another observation is that in $\mathrm{MBH}$ and MWH contexts, the handling CLP often does not occur alone. For instance, the handling CLP might be articulated simultaneously with a whole-entity CLP on the other hand describing the movement of either the holder or the held object. We think such cases should be

${ }^{21}$ Video available at http://rsl.nstu.ru/data/view/id/251/t/21461/d/23750. 
analyzed as coordination of predicates, as argued by Zwitserlood (2017). We leave the analysis of these structures for future research and focus on explaining the use of handling CLPs in isolation in Sect. 5.5.

\section{Our proposal}

In this section, we present a formal account of the properties of RSL CLPs discussed in the previous section. Since our account is based on the framework developed by Ramchand (2008a), we briefly outline her approach. ${ }^{22}$

\subsection{Theoretical framework}

Researchers working in various frameworks agree on the basic insight that argument structure is to a large extent dependent on event structure (see, for instance, Borer 2005; Levin and Rappaport Hovav 2005; Van Valin 2005; Ramchand 2008a).

For instance, there is a typologically robust pattern that the role of Agent is the most privileged thematic role for subject selection: in an unmarked sentence, the Agent will take on the function of subject, irrespective of the roles of the other arguments, so (24a) is possible but (24b) is not. This can be explained by looking at the event structure of predicates with an Agent: they always involve causation, that is, one event causing another event. In (24a) there is the event of building performed by the man, and the resulting state of the houses being built; the first event causes the second event. The Agent argument is associated with the causing event, and is thus the most "external" argument in the event structure.

a. The man builds houses.

b. *The houses build the man.

Another way in which event structure is related to argument structure is the choice of the object: the argument that 'measures out' the event described by the verb usually becomes the direct object (Tenny 1987). For instance, in (24a) above, the progress in the house-building event is measured out by the houses being built.

Ramchand (2008a) takes the idea that argument structure is dependent on event structure further. In her approach, thematic roles of arguments are directly derived from the positions they take in the syntactically encoded event structure. Consider the representation for the sentence 'John broke the glass' in (25). Note that this is a representation of the structure below the VP (the first phase, in Ramchand's terms), not of a full clause, so tense marking and agreement are not represented.

The event of John breaking the glass is decomposed into three separate sub-events: the initiation state, the process event, and the result state. Each of these events is expressed by a head (init, proc, and res), and the verb break is lexically associated

\footnotetext{
${ }^{22}$ Note that we do not claim that the RSL data could or should only be accounted for in Ramchand's framework. On the contrary, it is very likely that different formal analyses are applicable. Much more research would be needed to make a choice between different formal analyses for the RSL data. However, we consider it useful to stick to one commonly accepted framework in this paper, as this framework makes concrete predictions for CLPs in RSL which can be tested.
} 
with all of these heads. ${ }^{23}$ Each of the heads has a specifier position that gives rise to a thematic interpretation: Initiator is the subject of initiation (similar to Agent in a more traditional terminology), Undergoer is the subject of a process (such as movement or change), and the Resultee is the subject of the resulting state. Within this approach, it is possible that an argument will have a combined role: for instance, the glass in (25) is interpreted as Undergoer-Resultee, while John is the Initiator.

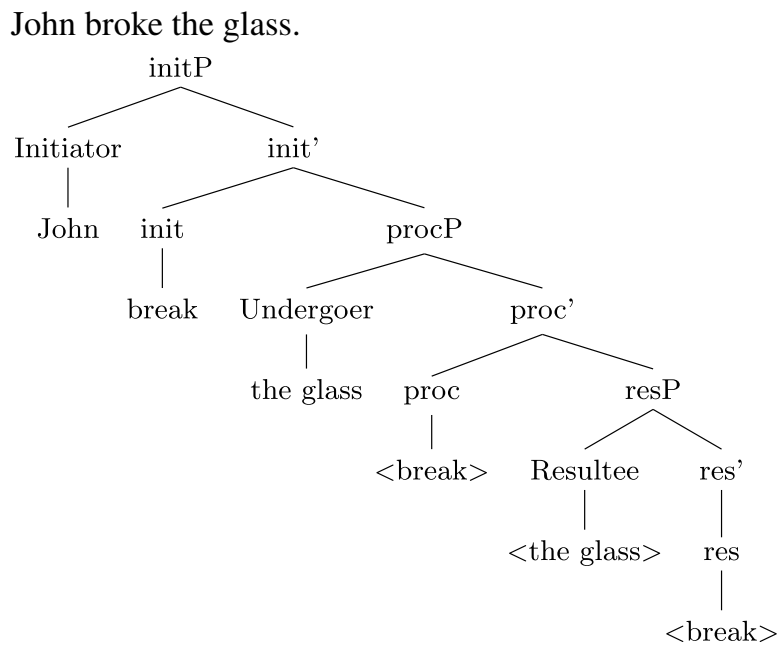

The subevents are by definition causally connected: that is, if subevent $\mathrm{A}$ is a complement of subevent B, B causes A. So the init state causes the proc event, and the proc event causes the res state (Ramchand 2008a:44).

In addition to taking other events as complements, the init, proc, and res heads can also take non-eventive complements, which Ramchand (2008a) calls Rhemes. For instance, in (26), the subject Karena is the Initiator-Undergoer, but the object two miles is clearly not a Resultee: instead, it is a rhematic Path argument (Ramchand 2008a:34).

(26) Karena jogged two miles.

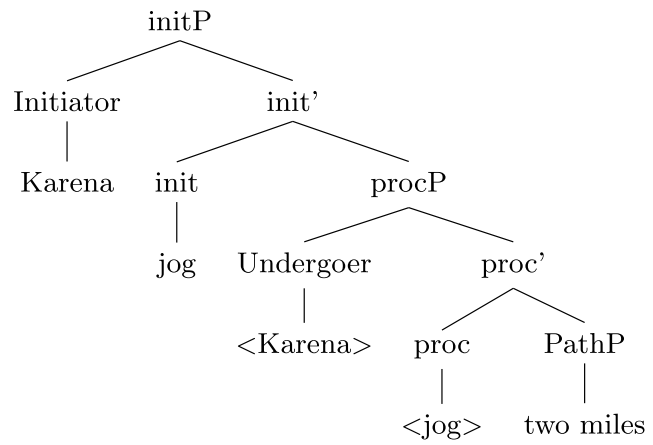

\footnotetext{
${ }^{23}$ So in Ramchand's approach break does not move from one head to another; it is simultaneously inserted in all three positions. This is represented by the $<$ break $>$ notation.
} 
As mentioned above, in this approach, verbs are lexically associated with particular event structures. For instance, the verb break in its lexical description will have the features $\{$ init, proc, res $\}$. Other verbs will have different sets of features. For instance, a process verb that does not imply change or movement (e.g. dance) will not have a res feature in its lexical description. However, its event structure can be extended, e.g. in a resultative construction: 'Ariel danced her shoes ragged.' In this sentence, the verb dance is associated with the proc head, while ragged is a complement of a zero res head, as in (27) (Ramchand 2008a:124).

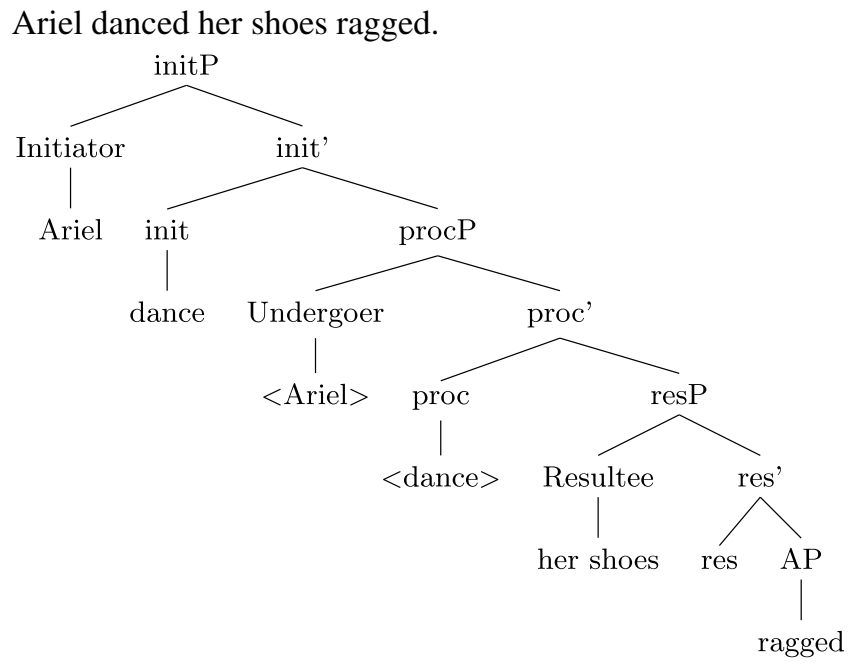

This example illustrates an important property of Ramchand's approach: it assumes the same underlying event structure for both simple verbs and syntactic constructions, such as the resultative construction in English. Therefore, the approach applies in a similar fashion to languages with different morphological strategies of expressing argument structure. Languages like English often associate the whole argument structure with a single lexical item (the verb), as in (25); additionally, syntactic resultative constructions and verbal particles can be used to extend the event structure, as in (27). In Russian, prefixes have been argued to modify argument structure, so a part of the event structure can be expressed by a verbal root, while another part is expressed by a prefix. Many languages use constructions involving multiple verbs (serial verb or light verb constructions), which again can be modeled by the same approach by assuming that different event heads are expressed by different verbs in these languages (Ramchand 2008a).

For us, the most relevant feature of this approach is that it makes a very strong prediction with respect to possible event structures. Specifically, the event structure illustrated in (28) is the maximal possible monoclausal structure with all three heads: init, proc, and res, and a rhematic non-event argument. In addition, the events associated with these heads form a clear causal chain, as described above. 


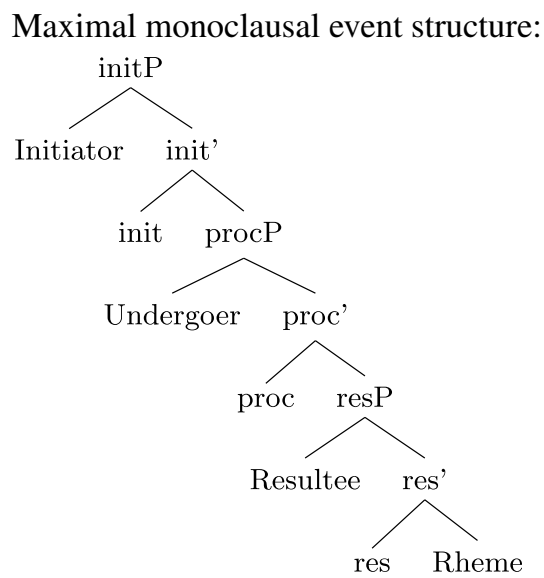

In her (2008a) book, Ramchand shows that this maximally possible event structure is enough to account for the basic verbal types in English, but she also discusses Russian and various Indic languages. In subsequent works (Ramchand 2008b; Ozarkar and Ramchand 2018), she also shows that, for instance, complex predicates in Bengali and Marathi that involve combinations of multiple verbs nevertheless fit the same restrictive event structure. Of course, complex multiclausal sentences can describe more complex events, but it seems that all monoclausal structures in spoken languages adhere to this restrictive pattern. As we will show in the next section, it appears that some CLPs in RSL require an extension of this basic structure.

\subsection{Whole-entity CLPs}

As we discussed in Sect. 4.1, whole-entity CLPs in RSL behave as intransitive unaccusatives: they have one argument, which is the Theme (Undergoer) that moves or is located, and the classifier refers to this argument.

We propose that the movement root in whole-entity CLPs is the proc head in the event structure, and the only argument is the subject of this event head, the Undergoer. The proc head takes a PathP (in the case of the MOVE root) or PlaceP (in the case of the BE root) complement, which can include locative arguments. We do not further discuss the locative arguments in this study. Finally, the classifier morpheme itself is an agreement marker, which we represent here as the head of an AgrP (but the exact implementation of agreement is not crucial to our analysis). The whole structure is represented in (29). ${ }^{24}$

\footnotetext{
${ }^{24} \mathrm{~A}$ reviewer pointed out that the root MOVE seems to be too abstract in the sense that it does not contribute any meaning to the structure. In fact, a combination of proc with PathP itself encodes motion along a path. The issue with roots in CLPs being very abstract and lacking traditional lexical meaning has indeed been discussed before, see e.g. Zwitserlood (2003). We cannot resolve this issue in this paper, but we can speculate. First, one can indeed say that there is no root like MOVE; the meaning of motion is fully encoded by the empty proc head in combination with the PathP. There is a problem, however, with the syntax-phonology interface, as we then would need to postulate some rule that would match this syntactic structure without any lexical item in the proc head to movement of the hand. Second, another option is to say that there is in fact additional meaning associated with the root, namely the demonstration component,
} 


$$
\text { MAN CL }{ }_{W E}(1)-M O V E
$$

'The man moves.'

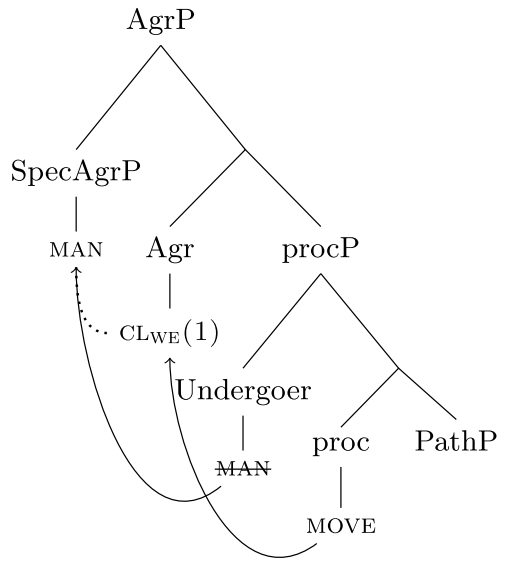

The only argument moves to the SpecAgrP position for agreement, and the verbal root MOVE moves to the head of the agreement projection via head movement, to combine with the classifier morpheme.

Furthermore, if we want to account for the transitive use of whole-entity CLPs (as in (11)) using the same structure, we only need to claim that the external argument is introduced above the VP (similar to what we will claim for body-part CLPs). The classifier handshape still is an agreement marker agreeing with the Undergoer argument, even if an external argument is present.

A general note on our analysis of the classifier as an agreement morpheme is due. Various researchers (Glück and Pfau 1998; Zwitserlood 2003) have provided arguments in favor of analyzing classifier morphemes as agreement markers (in DGS and NGT, respectively). The crucial piece of evidence for us consists of two elements: (1) the classifier is used alongside a full NP argument in the clause, so it is not an instance of noun incorporation (Meir 2001), and (2) the shape of the classifier is determined by the class of the argument it refers to. In Sect. 6.2, we further discuss another prediction that the agreement analysis makes, namely the expected pro-drop licensing by a classifier predicate. ${ }^{25}$

To sum up, the proposed structure for whole-entity CLPs captures the following facts:

- The whole-entity CLPs are intransitive unaccusative, because the verbal root is only associated with the proc head, so only one Undergoer argument is licensed. ${ }^{26}$

which we discuss in Sect. 6.3. Informally, the root comes with the additional signal saying 'interpret this movement iconically.'

${ }^{25}$ Note also that Kimmelman and Khristoforova (2018) have argued that whole-entity classifiers in RSL are in fact not agreement markers, but predicate modifiers associated with the Undergoer argument. If this is indeed the case, then the analysis in (29) has to be revised slightly. The main observation, namely that whole-entity classifiers do not determine argument or event structure, still holds.

${ }^{26} \mathrm{We}$ disregard the potential locative arguments here. 
Some instances of transitive use are also attested, so another argument can be introduced independently of the type of classifier.

- The shape of the classifier is dependent on the Undergoer argument of the verb, because the classifier is an agreement morpheme.

\subsection{Body-part CLPs}

As discussed in Sect. 4.2, body-part CLPs in RSL are transitive: they combine with a body-part argument (that undergoes the movement described by the CLP), and, optionally, the possessor of the body-part argument, which is the subject (if present). Importantly, the possessor subject is not interpreted thematically as Agent (recall example (13)).

Since the subject is not an Agent, or in Ramchand's (2008a) terminology, not an Initiator, we suggest that body-part CLPs in RSL have in fact the same underlying event structure as whole-entity CLPs: the verbal root is associated with the proc head, and it therefore licenses only the Undergoer argument (the body part). The body-part argument moves to the specifier of AgrP, headed by the classifier; the choice of classifier is achieved through agreement. This structure is represented in (30).

However, the possessor argument can also be the subject. It is clear that the possessor argument cannot be introduced by the init head because it is not an Initiator. It must therefore be hosted by some projection above the VP, similar to what happens with transitive uses of whole-entity CLPs. Specific details of the syntactic analysis for such cases lie beyond the scope of this paper. We only want to point out that this situation is reminiscent of the phenomenon of external possession attested in many spoken languages (Payne and Barshi 1999).

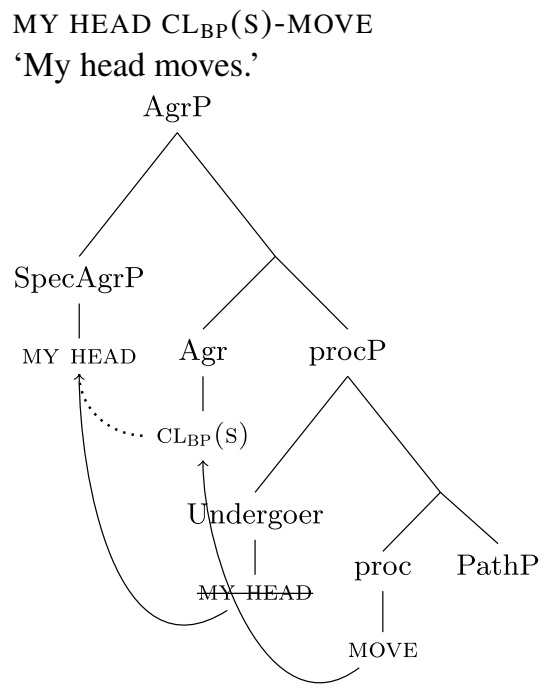


Our most important conclusion is that, in RSL, body-part CLPs are in fact very similar to whole-entity CLPs: the verbal root is the same in both cases, and the classifiers are agreement morphemes, agreeing with the only argument that is thematically licensed by the verb (the Undergoer). Thus in both cases, the classifier neither heads a projection that hosts arguments nor determines transitivity of the resulting predicate.

\subsection{The 'moving legs' CLP}

In Sect. 4.2, we demonstrated that the 'moving legs' CLP has a complex event structure. Specifically, it describes two events: the movement of the legs, which is controlled by the possessor, and the movement of the whole person, which does not have to be controlled by the moving person. The first event is expressed by the movement of the fingers, while the second event is expressed by the movement of the hand. Furthermore, this CLP can only have one overt argument: the moving person. ${ }^{27}$

Is it possible to associate the two events (the movement of the legs and the movement of the person) with the layers in the maximal event structure as in (28)? We argue that this is impossible. First, both events are dynamic (as they describe movement of the legs or the person), so they should be associated (at least ${ }^{28}$ ) with two proc heads. This would lead to the configuration in (31). However, this is not a possible configuration in Ramchand's (2008a) framework.

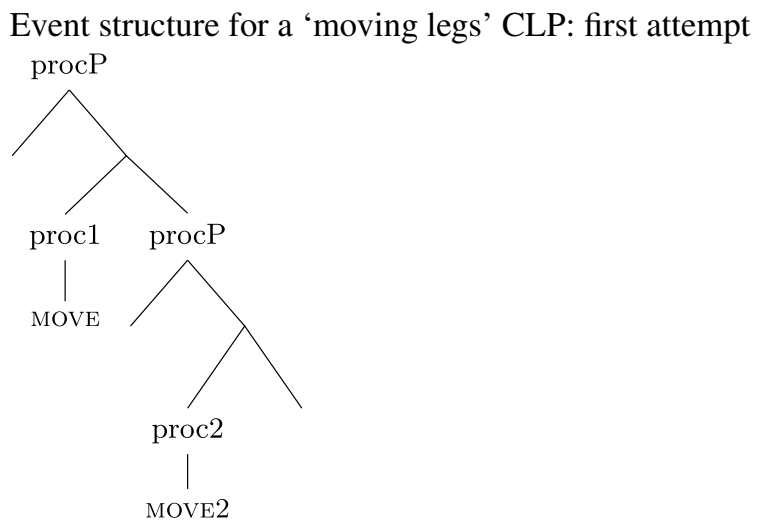

Moreover, even if we extended the possible configurations by allowing recursion of the proc layer to derive (31), it will necessarily be interpreted as a causal chain: one of the events causes the other event. However, we have seen that this is not feasible: the movement of the legs does not have to cause the movement of the person, and the movement of the person does not have to cause the movement of the legs, as example (17), repeated here as (32), demonstrates.

\footnotetext{
${ }^{27}$ Here, as with all CLPs, we disregard the Source and Goal arguments.

${ }^{28}$ The moving legs event should also have an init layer, as we discuss below.
} 
$\mathrm{CL}_{\mathrm{ML}}(2 \mathrm{~B}-\mathrm{MOVE} 2)-\mathrm{MOVE}$

'(The cat) flies through the air wiggling its legs.' 29

Another option is to say that the movement of the hand is the only verbal head ('to move'), and that the movement of the fingers is a Manner root ('by moving one's legs') that attaches to the main verb, similar to what is suggested for some manner verbs in English (Mateu and Acedo-Matellán 2012; Acedo-Matellán and Mateu 2015). Note that in (33), there is only one proc head (MOVE), to which a manner root MOVE2 is adjoined.

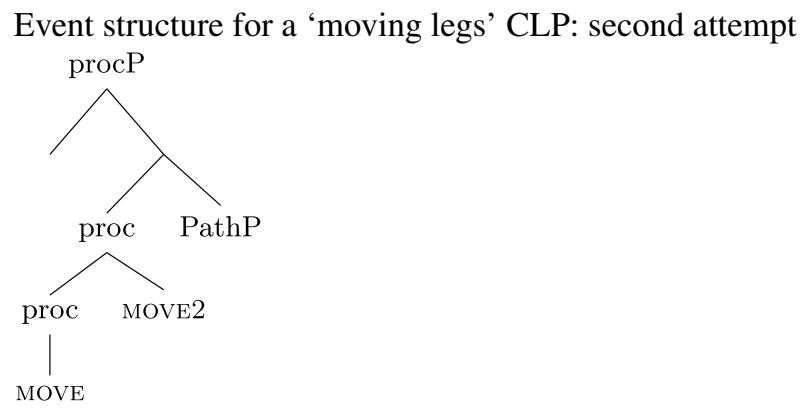

The main problem with this account is that, in RSL, both MOVE and MOVE2 can occur independently. As discussed in Sect. 4.2, a signer can use a CLP with the " $2 b$ " handshape without moving the fingers (to express the unaccusative meaning 'a person moves'), or use a CLP with the " $2 b$ " handshape and movement of the fingers, but not movement of the hand (to express the meaning 'to walk in place'). If the structure in (33) is correct, the latter usage is unexpected. In addition, both roots in this structure have a phonological expression, unlike English, where the manner root attaches to a $v$ head without a lexical item associated with it. Furthermore, the structure in (33) does not explain why the movement of the legs (which in this analysis is a manner specification) has to be controlled.

Finally, it is possible to say that the structure for the 'moving legs' CLP is the one represented in (34). The movement of the fingers is the proc head, and the movement of the hand is a part of PathP. There are also several problems with such an account. Firstly, it seems strange that the MOVE root which is a part of PathP, manages to attach to the verb, given that PathP would also contain the Source and Goal arguments. Secondly, and most importantly, the structure in (34) is basically the same as would be used for verbs of deliberate motion in English (e.g. walk), and for such verbs, it is clear that the Initiator does not only control the event identified by proc (walking, or moving your legs), but also the motion along the path identified by PathP. However, as discussed above, in RSL the motion along the path does not have to be controlled by the Initiator.

${ }^{29}$ Video available at http://rsl.nstu.ru/data/view/id/311/t/41250/d/42500. 
(34) Event structure for a 'moving legs' CLP: third attempt

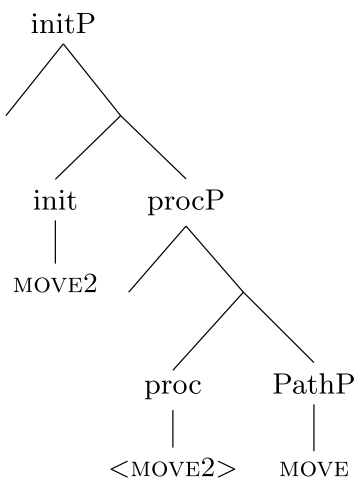

We therefore suggest that the 'moving legs' CLP in RSL has the event structure in (35). The left daughter of the XP is the event of a person moving his/her legs. As discussed above, this action is controlled, so we suggest that the MOVE2 verbal root is associated with both proc and init heads. Since there are both proc and init heads present, there are two specifier positions for (potentially) two arguments: the Initiator and the Undergoer. Given that the meaning of the whole complex is that a person moves his/her legs, we argue that the person is the Initiator, and the legs are the Undergoer: they are involved in the process described by the predicate of movement, controlled by the Initiator.

(35) Event structure for a 'moving legs' CLP: final attempt MAN CL $\mathrm{ML}_{\mathrm{L}}$ (2B-MOVE2)-MOVE

'The man walks.' (lit: 'The man moves his legs and moves.')

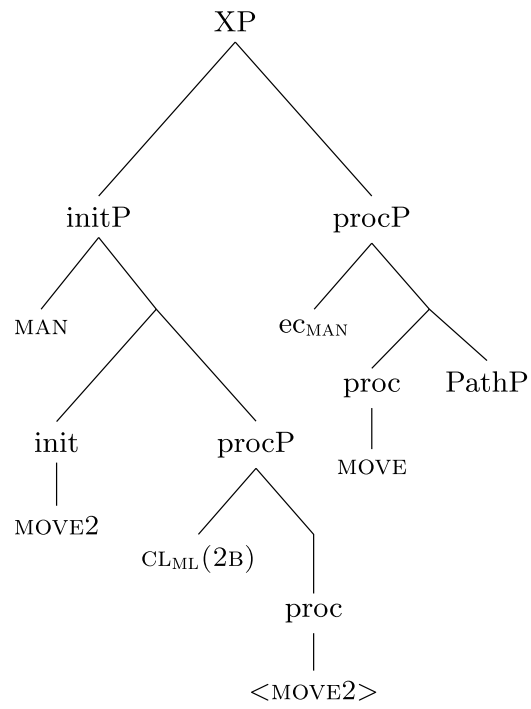

The MOVE2 root is different from the MOVE root used in whole-entity and body-part CLPs not only because it includes the init head, but also because it does not take 
a PathP as a complement: the movement of the legs cannot be further specified for Goal or Source arguments. Informally, the legs are not moving from one location to another; they are simply moving. The movement of the whole person is thus described by the right daughter of XP, and there the Source and Goal arguments can be specified, as this daughter contains PathP.

Morphologically, the verbal root MOVE2 is the movement of the fingers; the Initiator argument is a full noun phrase which becomes the subject, and the Undergoer argument is the $\mathrm{CL}_{\mathrm{ML}}-2 \mathrm{~B}$ handshape. The argument and the verbal root fuse in phonology, because neither handshape nor movement alone can constitute a well-formed sign. ${ }^{30}$

Turning to the right daughter of XP, it represents the event of a person moving in space. As discussed above, this movement is not necessarily controlled, so we suggest that the same movement root present in other classifier predicates discussed in the two previous sections is also present here. This MOVE root is only associated with the proc head and thus only licenses the presence of a single Undergoer argument (the moving person).

Morphologically, the verbal root in the right daughter of XP is just the movement of the hand. Since, as discussed for the MOVE2 root above, the movement of the hand cannot be physiologically realized without a handshape, it fuses with or cliticizes to the predicate in the left daughter in phonology. Note that after linearization MOVE will be adjacent to the $\mathrm{CL}_{\mathrm{ML}}(2 \mathrm{~B}-\mathrm{MOVE} 2)$ complex.

The only argument of the right daughter is an empty category. The nature of this empty category is unclear to us at the moment. However, we note that this construction seems similar to Serial Verb Constructions (SVCs) in Saramaccan (Veenstra 1996), where the internal argument of the second verb is necessarily empty. For instance, in (36) báli 'ball' is an overt argument of the first verb sikópu 'kick', but it cannot also surface as an overt pronominal argument of the second verb gó 'go'. Veenstra (1996) argues that this argument is either a PRO or a pro depending on the meaning of the SVC, namely on the sequential vs. simultaneous reading of the construction. Given that only the simultaneous reading of the two sub-events is available for the 'moving legs' CLPs in RSL, it is reasonable to suggest that the empty category is a PRO. However, much more research is necessary on this issue. ${ }^{31}$
A sikópu dí báli gó a dí wósu
3SG kick DET ball go LOC DET house
'He kicked the ball into the house.' OR
'He kicked the ball and went into the house.' (Veenstra 1996:125)

Finally, we need to address the nature of the XP. What we are trying to model in (35) is the finding that the two sub-events described by the 'moving legs' CLP have different event structures and are not in a causal relation with respect to each other. The only constraint is that these events are happening simultaneously. This can be

\footnotetext{
${ }^{30}$ One could argue that the Undergoer argument is incorporated into the verbal root after Head Movement (Baker 2009). However, more research is necessary to see whether this is indeed incorporation, or simply a phonological process.

${ }^{31}$ See also Aboh (2009) for a discussion on SVCs.
} 
modeled by saying that one of the events is adjoined to the other; so the XP is in fact an initP, with procP adjoined to it. A similar adjunction analysis has been suggested for some serial verb constructions expressing simultaneous events (Veenstra 1996; Chan 1997). Another option would be to analyze this structure as coordination. At this moment, we are not able to conclusively distinguish between the two options, so we leave it to future research. ${ }^{32}$

We find further evidence for the structure in the fact that each daughter of the XP can occur on its own, without the other daughter. As discussed in Sect. 4.2, the movement of the legs might be described without the movement of the person, e.g. in a situation of a person walking on a treadmill (18), and the movement of the person can be described without the movement of the legs (14b).

To sum up, our analysis of the 'moving legs' CLP is very different from our analysis for whole-entity and body-part CLPs. Firstly, the proposed event structure is more complex, as it no longer fits the maximal monoclausal event structure proposed by Ramchand (2008a). Secondly, the classifier handshape is not analyzed as an agreement marker, but as an argument referring to the legs.

\subsection{Handling CLPs}

In Sect. 4.3, we demonstrated that handling CLPs in RSL have a number of properties that we need to account for. Firstly, the hand is a necessary semantic component of the CLP (20). Secondly, the hand in the handling CLP does not have to move (21a). Finally and most importantly, handling CLPs do not only describe regular handling (19), but also what we call 'moving because handling' (22) and 'moving while handling' (23) scenarios, repeated here as (37) and (38).

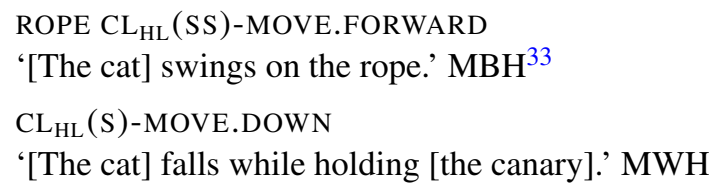

The latter issue shows that the two events (the holding event and the movement event) do not form a causal chain. So, by the same logic as discussed for the 'moving legs' CLP in 5.4 above, the event structure of handling CLPs in RSL does not fit the maximal monoclausal pattern suggested for spoken languages (28). It should come as no surprise that we account for these facts by decomposing the event structure of the handling CLPs into two complex sub-structures. Informally, we suggest that a handling CLP means 'An Initiator is causing his hand (Undergoer-Resultee) to be on an object (a Location), and it (the hand) moves.' The full representation for a handling CLP containing movement is given in (39).

\footnotetext{
${ }^{32}$ There are some indications that when SVCs in spoken languages involve coordination, this severely restricts interpretive possibilities (Basu and Wilbur 2010). Since we do not observe such restrictions in RSL, it could be used as an argument for the adjunction analysis.

${ }^{33}$ Video available at http://rsl.nstu.ru/data/view/id/251/t/21461/d/23750.
} 


\section{MAN STICK CL $\mathrm{HL}_{\mathrm{H}}(\mathrm{S})-\mathrm{MOVE}$}

'The man moves a stick.'

(lit: 'The man has his hand ${ }_{i}$ on the stick, and it ${ }_{i}$ moves.')

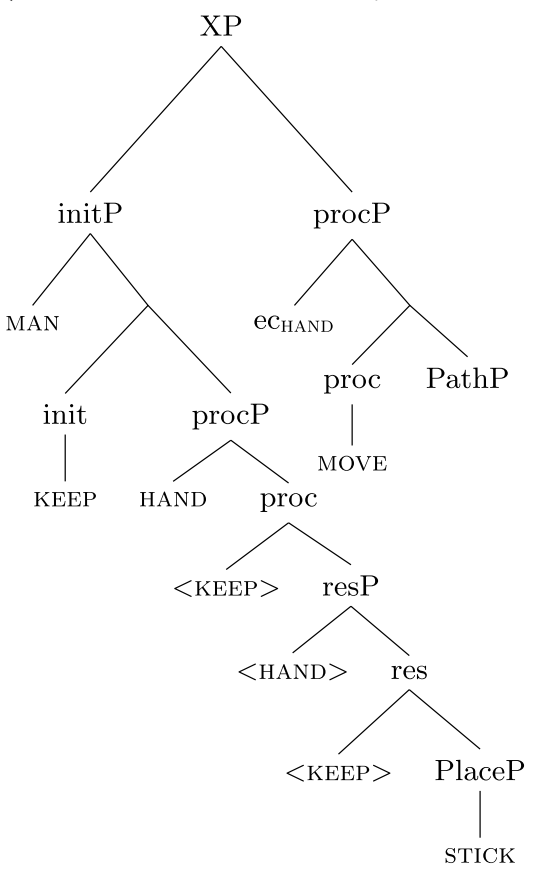

The left daughter of the XP in (39) describes the holding event. The verbal root there is glossed approximately as KEEP, which is associated with the init, proc, and res heads, and the res also selects for a locative Rheme. The init head is present because the holding event has to be controlled by the holder. The Undergoer-Resultee is the hand (expressed by the signer's hand itself): it is the argument that the Initiator causes to be in a particular result state. The result state here is in fact a locative construction: the Initiator causes the hand to be at the stick (which is a complement of the res head). ${ }^{34}$

We gloss the verbal root as KEEP, and not as, for instance, HOLD, because holding is not necessarily involved. In fact, a handling CLP can be used to describe a situation where someone moves a cup with the back of their hand, as in (40), illustrated in Fig. 8. The structure in the left daughter of XP is thus compatible with different locations of the hand with respect to the other object: the hand can be around the object, as in many examples, e.g. (37) and (38), or it can be touching the object, as in (40).

\footnotetext{
${ }^{34}$ In a series of papers, Wilbur argues for the Event Visibility Hypothesis (EVH); she argues that event structure is visible in phonology (Wilbur 2008, 2010). It is not our purpose in this paper to test this theory against RSL data. However, it seems that at least our analysis for the left daughter of XP in (39) is problematic for the EVH: while the event structure we propose is telic, as it has the res head, there is no movement with a change of a parameter as would be predicted by the EVH-in fact, there is no movement at all. As for the other event structures that we propose, they seem to be unproblematic for the EVH: mostly, CLPs have path movement, which either has or lacks an abrupt end point, and thus can be either telic or atelic.
} 

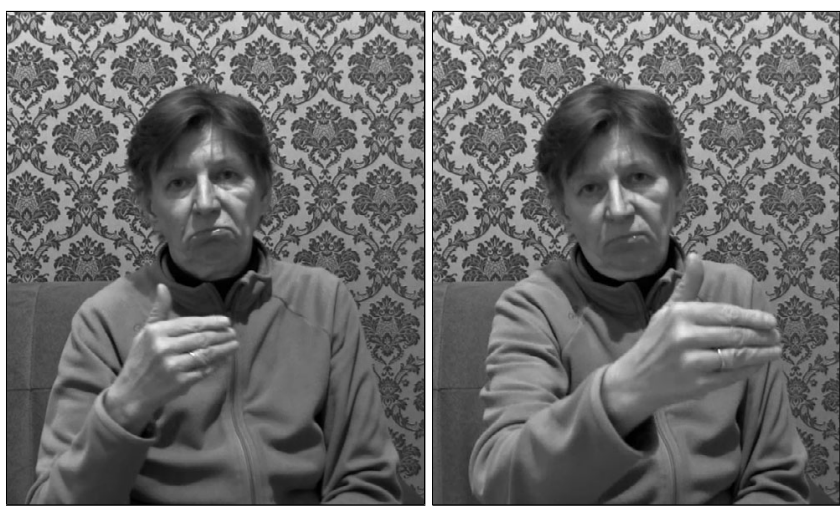

Fig. 8 Screenshots of the $\mathrm{CL}_{\mathrm{HL}}$ (B)-MOVE from example (40)

\section{IX-1 CUP CL $\mathrm{HL}_{\mathrm{HL}}$ (B)-MOVE}

'I moved the cup with the back of my hand.'

Note that this type of example is clearly problematic for accounts that postulate that the handshape in CLPs is in some form of agreement with the argument that is being moved (e.g. Glück and Pfau 1998), because in such examples, the handshape does not depend on the shape of the object. ${ }^{35}$

Morphologically, the Initiator argument and the Location argument are full noun phrases. The Resultee argument (the hand) is realized as the signer's hand itself, and it fuses with the verbal root KEEP in a way parallel to the 'moving legs' CLP model. The verbal root itself does not have a distinguishable form: together with the hand argument, it is realized as a particular configuration of the hand, e.g. as a curved hand when holding round objects, or as a flat hand when touching objects. We would argue that the shape of the hand in this case is determined not via agreement with an argument, but via an iconic demonstration procedure, which we further discuss in 6.3. The reason not to analyze the handshape as agreement here is the same as for the 'moving legs' argument in Sect. 5.4: the hand cannot be realized as an overt NP in the same clause.

The right daughter of the XP in (39) is basically the same as in the structure for the 'moving legs' CLP: it describes a potentially uncontrolled movement of the hand. That this movement can be uncontrolled is clear in the MBH situations (37). The verbal root MOVE is thus a proc head.

Again, as in the case of the 'moving legs' CLP, the verbal root in the right daughter of the XP contains movement only, so it is not a well-formed sign. Therefore, it

\footnotetext{
${ }^{35}$ One might decide that such cases of handling CLPs describing touching are a different construction altogether, and only account for the holding scenario. In this case, the left daughter of XP in (39) can get a simpler structure, namely the same one as the English verb hold would have: the holder is the Initiator, and the held object is the Undergoer-Resultee. However, this leads to another problem: if the hand is no longer an argument in the left daughter of XP in (39), it is unclear why it would not be expressed overtly in the right daughter. Our analysis accounts for this fact: the Undergoer argument in the right daughter of $\mathrm{XP}$ is a PRO controlled by the Undergoer-Resultee argument in the left daughter-and also allows us to analyze holding and touching cases uniformly.
} 
fuses with the handshape and the movement of the verbal sign in the left daughter, to form the complex CLP: $\mathrm{CL}_{\mathrm{HL}}(\mathrm{S})$-KEEP-MOVE. Notice that, after linearization, the two verbal roots will be adjacent, because in RSL, similarly to other sign languages, CLPs are clause-final (see all examples above). The Locative argument (the stick in (39)) will have to move to a specifier outside the VP.

The compositional meaning derived from the event structure in (39) is thus as follows: 'The man (Initiator) keeps his hand (Undergoer-Resultee) at the stick (Location), and it (the hand) moves.' It should be clear that this event semantics is compatible with all three contexts in which handling CLPs can be used. In regular handling, the man keeps his hand around the stick, and he deliberately moves his hand forward (thereby also moving the stick). In 'moving because handling' situations, the man keeps his hand around the stick, and the stick moves independently, causing the man's hand (and maybe also the man) to move. Finally, in 'moving while handling' situations, the man keeps his hand around the stick, and the man moves, but since he is holding the stick, the stick also moves.

We thus argue that the choice between the three meanings is not encoded in syntax. Instead, the linguistically-encoded meaning is compatible with all three scenarios, and the choice of interpretation is based on context/pragmatics.

Further evidence for the structure in (39) comes from the fact that the left daughter of the XP can be used without the right daughter. The hand in the handling CLP does not have to move, as example (21a), repeated here as (41), demonstrates. ${ }^{36}$ Of course, the right daughter can be used alone, in which case it would surface as a body-part CLP describing the movement of the hand not holding anything.

\section{MAN STICK $\mathrm{CL}_{\mathrm{HL}}(\mathrm{S})$-KEEP}

'The man holds a stick.' (lit.: 'The man keeps his hand around the stick.')

To sum up, our analysis for handling CLPs in RSL is very different from our analysis for whole-entity and body-part CLPs, but close to our analysis of the 'moving legs' CLP. The most important features of the analysis are (1) the CLP has a complex event structure which does not fit the maximal monoclausal event structure proposed by Ramchand (2008a), and (2) the classifier handshape is not an agreement morpheme, but an argument (the hand).

Our analyses for the 'moving legs' and handling CLPs, while similar, are also not identical. One difference between the 'moving legs' CLP and handling CLPs concerns the number of arguments: while the 'moving legs' CLP has only one overt argument (not counting the Source and Goal arguments) not fused with the verb, handling CLPs also have a Location argument (the object that is being held).

A major conclusion of this section, and to a large extent, of this paper in general, is that, at least in RSL, the relation between classifier type and argument structure is more complex than suggested by, for instance, Benedicto and Brentari (2004) for ASL. In RSL, different classifier types involve different phenomena: some classifiers are agreement markers (and thus are not really related to argument structure at all), while others are incorporated arguments. Contrary to Benedicto and Brentari (2004),

${ }^{36}$ We modified the example here to include the verbal root KEEP, which we only introduced in this section. 
we do not find support for the proposal that classifiers themselves introduce functional heads to host and assign thematic roles to arguments.

\section{Discussion}

\subsection{Event structure of CLPs larger than expected?}

In our analyses of the 'moving legs' and handling CLPs in RSL, we argued that they have an event structure that is more complex than predicted by Ramchand (2008a) for monoclausal structures: these CLPs involve an event structure in which the subevents do not form a causal chain but appear to belong to two independent sub-events. We have to ask ourselves what this means theoretically.

One option is to say that the 'moving legs' and handling CLPs in RSL are actually bi-clausal structures. The first clause then describes the first event, and the second clause describes the second event. Within such an approach, the fact that the event structure is complex does not constitute a problem, as the restrictions on how complex the event structure of a complex sentence can be are clearly much looser. However, this solution does not seem ideal.

Firstly, we would then need to claim that the bi-clausal structure can in fact be realized as a single one-handed sign. It is not clear what would be more far-fetched: to claim that event structure in sign languages can be more complex than expected, or to claim that single signs in sign languages can be bi-clausal structures. Secondly, it is very hard to find any evidence for the presence of two clauses within CLPs. Obviously, it is not possible to apply movement tests, because the putative clauses are realized as single signs. Other tests, such as, for instance, negation, would also not be directly applicable. In a bi-clausal structure, we would expect negation to be able to scope separately over one of the two clauses. However, in the case of CLPs, both manual and non-manual negation would be syntactically outside the level at which the two clauses are combined, so the lack of scopal ambiguity would not be informative.

We are thus more inclined to conclude that, in RSL (and probably other sign languages), some CLPs do in fact have a monoclausal event structure that is more complex than predicted by Ramchand (2008a) for spoken languages.

Some verbs in spoken languages look superficially similar to the handling CLPs in RSL in that they also describe two simultaneous events. For instance, (42) (Talmy 2017:2) describes a motion event and also a simultaneous sound emission event.

The hawk screeched across the sky.

However, it has been shown that these verbs in spoken languages do not in fact involve two separate event structures. Argument structure is determined by the motion event structure, and the sound emission verbal root is adjoined to the motion verbal head as manner (Mateu and Acedo-Matellán 2012; Acedo-Matellán and Mateu 2015). Above we have argued that such an analysis cannot account for the RSL data. First and foremost, the two events in RSL CLPs can in fact occur independently. Secondly, both verbs that we postulate for the RSL CLPs in fact have phonological expression. For 
the 'moving legs' CLP, one verb is realized as the hand-internal movement, and the other as the path movement of the hand, and for the handling CLPs, one verb is realized as a particular handshape, and the other as the path movement of the hand. Finally, the manner interpretation of one of the sub-events does not explain all restrictions imposed on arguments of the sub-events, such as the necessary presence of control over one of the events in both handling and 'moving legs' CLPs. ${ }^{37}$

While this paper is devoted to the argument and event structure of CLPs, it is necessary to say a couple of words about other verbs in RSL. We expect that nonclassifier predicates in RSL have the same event structures and therefore the same argument structures as proposed for verbs in spoken languages. In fact, Kimmelman (2018a) has recently analyzed lexical verbs in RSL demonstrating that they fit neatly into verb classes widely attested in spoken languages. Moreover, whole-entity CLPs and body-part CLPs in RSL are also not special in terms of event and argument structure: they are simply predicates of motion, which happen to lack phonological specification for handshape, so they are combined with classifier morphemes. However, we have argued that the 'moving legs' and handling CLPs in RSL have complex event structures, and we hypothesize that non-classifier predicates in RSL (or other signed or spoken languages) will not have these complex event structures.

Finally, it is important to note that we are not the first to claim that event structure in classifier predicates is more complex than event structure of verbs in spoken languages. Bradley (2013) argued, in particular, that CLPs in ASL do not obey some of the constraints on macro-events identified by Bohnemeyer et al. (2007). For instance, verbs in spoken languages can either encode or entail change of direction in the path, but not both (Unique Vector Constraint), but CLPs in ASL can both encode and entail change of direction. At the same time, lexical verbs in ASL obey the constraints. Another example is provided by Calderón Verde et al. (2018), who recently argued for a complex event structure in CLPs in Sign Language of Cuba.

It would be interesting to see whether all the differences in event structures between CLPs and other verbs in spoken and signed languages can be derived from a single underlying mechanism, such as demonstration (discussed below). However, this goes far beyond the scope of this paper.

\subsection{Classifiers as agreement markers?}

Some of the influential previous accounts of CLPs analyzed classifiers as agreement markers (Glück and Pfau 1998; Zwitserlood 2003). Benedicto and Brentari (2004) analyze classifiers as functional heads which introduce functional projections to host arguments, but also participate in agreement with the argument. However, in our analysis, only whole-entity and body-part classifiers are agreement markers, while in the 'moving legs' and handling CLPs, the handshape is analyzed as an argument.

In Sect. 5, we discussed two main arguments to analyze some, but not other classifier handshapes as agreement morphemes. Firstly, the handshapes in whole-entity

\footnotetext{
${ }^{37}$ A better parallel to the complex event CLPs in RSL might be represented by some SVCs, like the ones in Saramaccan discussed above. In Veenstra's (1996) analysis the two verbs in SVCs are not in a complementation relation; instead, the combination is formed via adjunction. Further research is necessary to show similarities and differences between SVCs and CLPs in sign languages.
} 
and body-part CLPs co-occur with overt co-referent arguments in the same clause, so they cannot be instances of incorporation. For the 'moving legs' and handling handshapes, the opposite applies: they cannot co-occur with an overt argument (that is, the legs or the hand argument). Secondly, the choice of whole-entity and bodypart classifier handshapes is dependent on the argument, which is nicely modeled as Spec-Head agreement. For the 'moving legs' CLP, the handshape actually cannot be changed at all. For handling CLPs, the handshape does change depending on the way the handling is performed (but not necessarily depending on the shape of the object being moved), but we model this via demonstration in Sect. 6.3.

However, Glück and Pfau (1998) and Zwitserlood (2003) discuss another argument to analyze classifiers as agreement markers, namely the fact that, in DGS and NGT, they license pro-drop (see also Lillo-Martin 1986 for the first discussion of the relation between pro-drop and agreement in ASL). Most sign languages, including DGS and NGT, have various classes of verbs, including plain (non-agreeing) and agreeing verbs. Agreeing verbs agree with locations of their arguments (see Pfau et al. 2018 for a recent syntactic account). ${ }^{38}$ It turns out that agreeing verbs, in contrast to plain verbs, license pro-drop. Consider (43a): pro-drop of the pronoun co-referent with the topicalized constituent MAN-A is not possible, because the verb BUY is plain. In (43b), the verb B-SHOW-A is spatially modified to agree with (the locations associated with) the subject and the object; in such cases, pro-drop is possible. In the same way, CLPs also license pro-drop of the argument referred to by the classifier (43c). Whole-entity CLPs also license pro-drop. Therefore, it is plausible to analyze the classifier morphemes as agreement.

DGS, adapted from Glück and Pfau (1998:69-70)

a. *MAN-A $\mathrm{A}_{\mathrm{i}}, \mathrm{CHILD}$ THINK pro $_{\mathrm{i}}$ BOOK BUY

'This $\operatorname{man}_{i}$, the child thinks, he $\mathrm{i}_{\mathrm{i}}$ buys the book.'

b. WOMAN-Ai, CHILD THINK MAN-B pro $\mathrm{i}_{\mathrm{B}}$ BOOK B-SHOW-A

'This Woman $_{i}$, the child thinks, the man shows her ${ }_{i}$ the book.'

c. GLASS-A $\mathrm{A}_{i}$, CHILD THINK MAN pro TABLE-B B-CL $_{\mathrm{HL}}(\mathrm{C})-\mathrm{TAKE}$

'This glass $s_{i}$, the child thinks, the man takes it ${ }_{i}$ off the table.'

Our analysis for RSL thus predicts that whole-entity and body-part CLPs should be able to license pro-drop (because these classifiers are agreement morphemes), while for instance handling CLPs should not license pro-drop of the Initiator argument or of the object that is being held and moving. It turns out, however, that all types of CLPs license pro-drop: compare (44a) with a whole-entity CLP to (44b) with a handling CLP.

a. BOOK-A $\mathrm{A}_{i}$, BOY THINK pro $\mathrm{SHELF} \mathrm{CL}_{\mathrm{WE}}(\mathrm{B})$-BE.AT

'This book $\mathrm{k}_{\mathrm{i}}$, the boy thinks, $\mathrm{it}_{\mathrm{i}}$ is on the shelf.'

\footnotetext{
${ }^{38}$ Recently, the traditional division of verbs into agreeing and plain has been questioned by e.g. Lourenço and Wilbur (2018), who argued for Brazilian Sign Language that all verbs agree by co-localization, except for the ones that are phonologically restricted. If this is correct, it raises questions about the proposed relation between agreement and pro-drop discussed below. Clearly more research is needed on this relation, as we also show for classifier predicates.
} 
b. BOOK-A $\mathrm{A}_{\mathrm{i}}$, BOY THINK IX-B MAN pro $\mathrm{SHELF} \mathrm{CL}_{\mathrm{HL}}$ (fO)-MOVE

'This book $\mathrm{k}_{\mathrm{i}}$, the boy thinks, the man has put $\mathrm{it}_{\mathrm{i}}$ on the shelf.'

This could seem to be counter-evidence to our analysis of different classifiers as different phenomena in RSL. However, it further turned out that neither plain nor agreeing verbs license pro-drop in RSL in such contexts (45). Specifically, the agreeing verb SEE-A, despite being marked for object agreement with the BOOK argument, does not license pro-drop of this argument. This means that pro-drop in RSL is not licensed by agreement (see Kimmelman (2018b) for a discussion). This is not entirely surprising given how different pro-drop licensing is cross-linguistically, at least in spoken languages (Biberauer et al. 2010; Barbosa 2011a,b).

a. *BOOK- $\mathrm{A}_{\mathrm{i}}$, BOY THINK MAN IX-B BUY pro

'This book $\mathrm{k}_{\mathrm{i}}$, the boy thinks the man bought $\mathrm{it}_{\mathrm{i}}$.'

b. *BOOK-A $\mathrm{A}_{i}$, BOY THINK MAN IX-B SEE-A pro

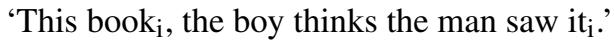

We thus maintain that whole-entity and body-part classifiers are agreement markers while the handling and 'moving legs' handshapes are not. ${ }^{39}$ The fact that all CLPs license pro-drop is not related to agreement, but to some other properties of CLPs.

\subsection{The role of demonstration}

Finally, let us return to the issue of iconicity and demonstration. As we discussed at the very beginning of the paper, CLPs are highly iconic. However, so far, we have completely ignored this iconicity. The reason for this is that we are convinced that the underlying grammatical properties of classifier predicates have to be linguistic in nature, as they are used as linguistic entities (predicates), and have linguistic properties. Specifically, they have argument structure: they combine with certain arguments; the number of arguments and their thematic roles are restricted. And as it turns out, it is possible to describe the argument and event structures of the CLPs using the same framework that has been applied to spoken languages.

Still, the iconic part of CLPs also has to be modeled. Fortunately, this has already been done, at least for ASL. In particular, Davidson (2015) argues that CLPs in ASL take an additional demonstration argument. A demonstration, informally, is some act performed by the speaker/signer, which reproduces some properties of the event that is being described. For instance, in spoken languages, demonstration is involved in contexts of quotation. In (46a) the speaker might imitate John's intonation, tone of voice, feelings, etc. Davidson (2015) provides a formal semantic analysis of demonstration. Without going into details, the semantic representation for (46a) is (46b). This means that John performed an event (namely, saying that he is happy), and there is a demonstration $d_{l}$ (John's words performed by the speaker) which has some similarity to this event.

\footnotetext{
${ }^{39}$ Recall also that Kimmelman and Khristoforova (2018) argued that whole-entity classifiers in RSL are not agreement markers, but predicate modifiers. This is largely compatible with our analysis, and deserves further investigation.
} 
English (Davidson 2015:488)

a. John said "I'm happy."

b. ヨe.[agent $(\mathrm{e}, \mathrm{John}) \wedge$ demonstration $\left.\left(\mathrm{d}_{1}, \mathrm{e}\right) \wedge \operatorname{saying}(\mathrm{e})\right]$

Similarly, for CLPs in ASL, Davidson (2015) suggests that, in addition to the linguistic elements (the classifier morpheme, the verbal root, etc.), the movement of the sign involves a demonstration. For instance, (47a) is (47b). In her analysis, the classifier morpheme has a meaning (the flatobject part), and the verbal root has the meaning (moving(e)), but, additionally, there is a demonstration, which means that the movement of the hand in some relevant aspects resembles the movement of the book. The meaning of demonstration is given in $(47 \mathrm{c})$.
ASL (Davidson 2015:495)
a. BOOK $\mathrm{CL}_{\mathrm{WE}}(\mathrm{B})$-MOVE
'A book moves.'
b. $\exists$ e. $[$ theme $(e$, book $) \wedge$ flatobject $(\mathrm{x}) \wedge$ moving $(\mathrm{e})$ $\wedge$ demonstration $\left.\left(\mathrm{d}_{1}, \mathrm{e}\right)\right]$
c. $[[$ the gestural movement of the hand $]]=\mathrm{d}_{1}$

She applies the same analysis to handling CLPs, which for her have another argument (an Agent), but the demonstration works in the same way.

We think that this analysis of the iconic component of CLPs is directly compatible with our analysis of whole-entity and body-part CLPs in RSL. The movement in these CLPs is interpreted as a verbal root MOVE, which also includes demonstration (48), so the shape, speed, and manner of the movement might resemble the movement of the object in the real world. We would only need to remove the flatobject $(x)$ part of (47b), because, in our analysis, the classifier is an agreement marker and does not have its own semantics.

$$
\text { MOVE: } \lambda \text { e. }\left[\operatorname{moving}(e) \wedge \text { demonstration }\left(\mathrm{d}_{1}, \mathrm{e}\right)\right]
$$

For the 'moving legs' CLP, two separate demonstrations have to be involved: one is associated with the movement of the hand $\left(\mathrm{d}_{1}\right)$, and one is associated with the movement of the fingers $\left(\mathrm{d}_{2}\right)$, as both can have iconic interpretations. This is schematically represented in (49). ${ }^{40}$
a. MAN $\mathrm{CL}_{\mathrm{ML}}(2 \mathrm{~B}$-MOVE2)-MOVE
'A man moves his legs and moves forward.'
b. MOVE: $\lambda$ e. $\left[\right.$ moving $\left(\mathrm{e}_{1}\right) \wedge$ demonstration $\left.\left(\mathrm{d}_{1}, \mathrm{e}_{1}\right)\right]$
c. MOVE2: $\lambda$ e. $\left[\right.$ moving $\left(\mathrm{e}_{2}\right) \wedge$ demonstration $\left.\left(\mathrm{d}_{2}, \mathrm{e}_{2}\right)\right]$
d. Whole clause: $\exists$ e. $\left[\right.$ theme $\left(\mathrm{e}_{1}, \mathrm{man}\right) \wedge \operatorname{moving}\left(\mathrm{e}_{1}\right) \wedge \operatorname{demonstration}\left(\mathrm{d}_{1}, \mathrm{e}_{1}\right)$ $\wedge \operatorname{agent}\left(\mathrm{e}_{2}, \mathrm{man}\right) \wedge$ theme $\left(\mathrm{e}_{2}, \mathrm{legs}\right) \wedge \operatorname{move}\left(\mathrm{e}_{2}\right)$
$\wedge$ demonstration $\left.\left(\mathrm{d}_{2}, \mathrm{e}_{2}\right)\right]$
e. $\quad[[$ the gestural movement of the hand $]]=\mathrm{d}_{1}$

\footnotetext{
${ }^{40}$ We use the labels agent and theme here, instead of Initiator and Undergoer, to stay close to Davidson's (2015) terminology. Note also that Ramchand (2008a) provides an explicit account of how event structures are compositionally interpreted, so the representations in (49) and (50) can be derived.
} 


\section{f. [[the gestural movement of the fingers $]]=\mathrm{d}_{2}$}

Finally, our analysis of handling CLPs in RSL also involves two demonstrations. One demonstration is associated with the verbal root MOVE, and it works in the same way as with whole-entity and body-part CLPs: the movement resembles the movement of the object in the real world. However, for the other event (the hand being in a locative relationship with respect to the handled object), we think that the handshape itself is interpreted as demonstration. This is illustrated in (50).
a. MAN STICK $\mathrm{CL}_{\mathrm{HL}}(\mathrm{S})$-KEEP-MOVE
'A man holds the stick and it moves.'
b. MOVE: $\lambda$ e. $\left[\right.$ moving $\left(\mathrm{e}_{1}\right) \wedge$ demonstration $\left.\left(\mathrm{d}_{1}, \mathrm{e}_{1}\right)\right]$
c. $\mathrm{CL}_{\mathrm{HL}}(\mathrm{s}): \lambda \mathrm{e} \cdot\left[\operatorname{keep}\left(\mathrm{e}_{2}\right) \wedge \operatorname{demonstration}\left(\mathrm{d}_{2}, \mathrm{e}_{2}\right)\right]$
d. Whole clause: $\exists$ e. $\left[\right.$ theme $\left(\mathrm{e}_{1}, \mathrm{man}\right) \wedge \operatorname{moving}\left(\mathrm{e}_{1}\right) \wedge$ demonstration $\left(\mathrm{d}_{1}, \mathrm{e}_{1}\right)$ $\wedge$ agent $\left(e_{2}\right.$, man $) \wedge$ theme $\left(e_{2}\right.$, hand $) \wedge \operatorname{location}\left(e_{2}\right.$, stick $)$ $\wedge \operatorname{keep}\left(\mathrm{e}_{2}\right) \wedge$ demonstration $\left.\left(\mathrm{d}_{2}, \mathrm{e}_{2}\right)\right]$
e. $[[$ the gestural movement of the hand $]]=\mathrm{d}_{1}$
f. $[[$ the shape of the hand $]]=\mathrm{d}_{2}$

This way we account for the fact that the shape of the hand is actually reflecting the real-life shape of the hand performing some action. This demonstration does not directly refer to the object that is being handled, as the shape of the object does not always have a direct influence on the shape of the hand (recall (40)).

Finally, our analysis, according to which handling classifier handshapes involve demonstration, while whole-entity and body-part classifier handshapes are purely morphological, seems to be supported by recent psycholinguistic research discussed in Sect. 2.1 (Sehyr and Cormier 2015). Nevertheless, further research is clearly needed to pin down the iconic aspects of CLPs in RSL, as well as in other sign languages. Importantly we already have the tools to formally model these iconic aspects (see also Schlenker (2014)).

\section{Conclusions}

In this paper, we analyzed argument and event structures of the major types of classifier predicates in Russian Sign Language. We used a combination of naturalistic corpus data and data elicited trough various techniques. We argued that whole-entity and body-part classifiers are agreement markers, while the 'moving legs' and handling classifiers are in fact arguments fused with the verbal root. Concerning event structure, we argued that whole-entity and body-part CLPs contain the MOVE root which is a proc head (it is a dynamic event describing the movement of a single Undergoer argument). In contrast, both the 'moving legs' and the handling CLPs have a complex event structure with two verbs, where a movement event is adjoined to another event (either the movement of the legs, or a handling event). We modeled these insights in Ramchand's (2008a) framework.

Our analysis has two theoretical implications. Firstly, we demonstrated that, at least in RSL, classifier type does not straightforwardly determine argument structure, 
and that classifiers are not functional heads determining thematic roles of arguments, as suggested by Benedicto and Brentari (2004) for ASL. Secondly, we showed that the event structure associated with some classifiers is complex and does not comply with the predictions of Ramchand's (2008a) model.

One final issue that we want to mention is whether our model of CLPs in RSL could be applied to other sign languages. Previous research on other sign languages suggests that whole-entity CLPs have very similar argument and event structures cross-linguistically, and we would therefore expect our model to be applicable. Bodypart CLPs in ASL are intransitive (or transitive underlyingly, but with the internal argument never expressed as a full NP in the sentence), in contrast to what we observed in RSL, so our analysis is not directly applicable. We do not know any detailed descriptions of the analogues of the 'moving legs' CLP for other sign languages, so it is difficult to make predictions. In our analysis, this CLP has a verbal root MOVE2, which selects the 'legs' argument. Other sign languages might not have the same root. Finally, for handling CLPs in most other sign languages, the more complex event structures that we propose for RSL have not been explicitly described (see Zwitserlood 2003 and Özyürek 2012 for some exceptions). However, through our experience in conducting research on several other sign languages, we expect that handling CLPs in those languages behave in a similar way: they should not only be compatible with regular handling, but also with the other two contexts, and the hand should be a semantic part of these predicates. We expect handling CLPs to be cross-linguistically similar because of the relatively large role of demonstration in such constructions. We therefore think that the main insights of our analysis of handling CLPs will have cross-linguistic validity.

\section{Annotation conventions}

Signs are glossed in SMALL CAPS; CL stands for classifier, followed by a subscript indicating the classifier type (we - whole-entity, hl - handling, bp - body part, $\mathrm{ml}$ moving legs), and followed between brackets by a symbol referring to the handshape. Fingerspelled words are glossed with dashes (e.g. M-A-R-I-S-A). Locations in space are glossed with letters (A, B, etc.), and these letters are used in combination with pronouns glossed as IX for index (e.g. IX-A 'he') and with agreeing verbs (e.g. LOOKA 'look at him'); semantic referential indexes are glossed as non-capitalized subscript (e.g. $\mathrm{MAN}_{\mathrm{i}}$ ). For the sake of space, nonmanual markers are omitted in all examples. When two hands are producing two different signs simultaneously, they are glossed on separate lines starting with $\mathrm{H} 1$ and $\mathrm{H} 2$.

We refer to handshapes with letters or numbers that are expressed with these handshapes in the ASL fingerspelling system, with the exception of the "1-l" handshape which is a handshape used for fingerspelling in RSL, but not in ASL. All the handshapes can be viewed at https://aslfont.github.io/Symbol-Font-For-ASL/asl/ handshapes.html (accessed 12 March 2019). The correspondences between the symbols we use and the names on the webpage in the Gloss column are as follows: $1-1$, $2-\mathrm{V}, 2 \mathrm{~b}-$ Bent-V, 5b - Bent-5 Claw, 3 - 3, B - B, C - C, F - F, fO - Flat-O, S - S, $1-\mathrm{L}-1-1$. 
Acknowledgements This research was supported by the Dutch Science Foundation (NWO, grant number 360-70-520). We are also grateful to Marloes Oomen, Vanja de Lint, Gillian Ramchand, Diane LilloMartin, the three anonymous reviewers, and the audiences at GLOW 40 and FEAST 2017 for their comments. We wish to thank the RSL signers who participated in this research.

Publisher's Note Springer Nature remains neutral with regard to jurisdictional claims in published maps and institutional affiliations.

Open Access This article is distributed under the terms of the Creative Commons Attribution 4.0 International License (http://creativecommons.org/licenses/by/4.0/), which permits unrestricted use, distribution, and reproduction in any medium, provided you give appropriate credit to the original author(s) and the source, provide a link to the Creative Commons license, and indicate if changes were made.

\section{References}

Aboh, Enoch O. 2009. Clause structure and verb series. Linguistic Inquiry 40: 1-33.

Acedo-Matellán, Victir, and Jaume Mateu. 2015. From syntax to roots: A syntactic approach to root interpretation. In The syntax of roots and the roots of syntax, eds. Artemis Alexiadou, Hagit Borer, and Florian Schäfer, 14-32. Oxford: Oxford University Press.

Baker, Mark C. 2009. Is head movement still needed for noun incorporation? Lingua 119(2): 148-165.

Barbosa, Pilar. 2011a. Pro-drop and theories of pro in the Minimalist Program part 1: Consistent null subject languages and the Pronominal-Agr Hypothesis. Language and Linguistics Compass 5(8): 551-570.

Barbosa, Pilar. 2011b. Pro-drop and theories of pro in the Minimalist Program part 2: Pronoun deletion analyses of null subjects and partial, discourse and semi pro-drop. Language and Linguistics Compass 5(8): 571-587.

Basu, Debarchana, and Ronnie B. Wilbur. 2010. Complex predicates in Bangla: An event-based analysis. Rice Working Papers in Linguistics 2: 1-19.

Benedicto, Elena, and Diane Brentari. 2004. Where did all the arguments go?: Argument-changing properties of classifiers in ASL. Natural Language and Linguistic Theory 22(4): 743-810.

Benedicto, Elena, Sandra Cvejanov, and Josep Quer. 2007. Valency in classifier predicates: A syntactic analysis. Lingua 117(7): 1202-1215.

Biberauer, Theresa, Anders Holmberg, Ian Roberts, Michelle Sheehan, eds. 2010. Parametric variation: Null subjects in minimalist theory. Cambridge: Cambridge University Press.

Bohnemeyer, Jürgen, Nicholas J. Enfield, James Essegbey, Iraide Ibarretxe-Antunano, Sotaro Kita, Friederike Lüpke, and Felix K. Ameka. 2007. Principles of event segmentation in language: The case of motion events. Language 83(3): 495-532.

Borer, Hagit. 2005. The normal course of events, Vol. 2. Oxford: Oxford University Press.

Bradley, Charles. 2013. Motion events and event segmentation in American Sign Language. Master's thesis, Purdue University.

Burkova, Svetlana. 2012-2015. Russian Sign Language Corpus. Available at http://rsl.nstu.ru/.

Calderón Verde, Alicia, Donny Wilson Limonta, Gilma Cervantes Solino, Ariel Hernández Hernández, and Elena Benedicto. 2018. Path, process and (a)telicity in space: Motion predicates in LSCu, Sign Language of Cuba. Formal and Experimental Advances in Sign Language Theory (FEAST) 2: 1-15.

Chan, Yin-wa. 1997. Semantic interpretation and ambiguity in Chinese Serial Verb Constructions. PhD diss., The University of Hong Kong.

Cogill-Koez, Dorothea. 2000. A model of signed language classifier predicates as templated visual representation. Sign Language \& Linguistics 3(2): 209-236.

Davidson, Kathryn. 2015. Quotation, demonstration, and iconicity. Linguistics and Philosophy 38(6): 477520.

de Lint, Vanja. 2018. NGT classifier constructions. Sign Language \& Linguistics 21(1): 3-39.

Emmorey, Karen, and Melissa Herzig. 2003. Categorical versus gradient properties of classifier constructions in ASL. In Perspectives on classifier constructions in signed languages, ed. Karen Emmorey, 222-246. Mahwah: Lawrence Erlbaum Associates. 
Glück, Susanne, and Roland Pfau. 1998. On classifying classification as a class of inflection in German Sign Language. In Sixth annual Conference of the Student Organization of Linguistics in Europe (ConSOLE) 5, eds. Tina Cambier-Langeveld, Anikó Lipták, and Michael Redford, 59-74. Leiden: SOLE.

Grose, Donovan. 2008. The geometry of events: Evidence from English and ASL. PhD diss., Purdue University.

Grose, Donovan, Ronnie B. Wilbur, and Katharina Schalber. 2007. Events and telicity in classifier predicates: A reanalysis of body part classifier predicates in ASL. Lingua 117(7): 1258-1284.

Kegl, Judy. 1990. Predicate argument structure and verb-class organization in the ASL lexicon. In Sign Language research: Theoretical issues, ed. Ceil Lucas, 149-175. Washington: Gallaudet University Press.

Kimmelman, Vadim. 2018a. Basic argument structure in Russian Sign Language. Glossa: A Journal of General Linguistics 3(1): 116.

Kimmelman, Vadim. 2018b. Null arguments in Russian Sign Language. Formal and Experimental Advances in Sign Language Theory (FEAST) 1: 27-38.

Kimmelman, Vadim, and Evgeniia Khristoforova. 2018. On the nature of classifiers in Russian Sign Language. Budapest. Paper presented at GLOW41.

Levin, Beth, and Malka Rappaport Hovav. 2005. Argument realization. Cambridge: Cambridge University Press.

Lillo-Martin, Diane. 1986. Two kinds of null arguments in American Sign Language. Natural Language and Linguistic Theory 4(4): 415-444.

Lourenço, Guilherme, and Ronnie B. Wilbur. 2018. Are plain verbs really plain?: Colocalization as the agreement marker in sign languages. Formal and Experimental Advances in Sign Language Theory (FEAST) 2: 68-81.

Mateu, Jaume, and Victor Acedo-Matellán. 2012. The manner/result complementarity revisited: A syntactic approach. In The end of argument structure? eds. Maria C. Cuervo and Yves Roberge, 209-228. Bingley: Emerald Group.

Meir, Irit. 2001. Verb classifiers as noun incorporation in Israeli Sign Language. In Yearbook of Morphology 1999, eds. Gerard Booij and Jacob van Marle, 299-319. Dordrecht: Kluwer.

Oomen, Marloes. 2017. Iconicity in argument structure: Psych-verbs in Sign Language of the Netherlands. Sign Language \& Linguistics 20(1): 55-108.

Ozarkar, Renuka, and Gillian Ramchand. 2018. Structure matching and structure building in Marathi complex predicates. Journal of South Asian Linguistics 8(1): 3-30.

Özyürek, Asli. 2012. Gesture. In Sign language: An international handbook, eds. Roland Pfau, Markus Steinbach, and Bencie von Woll, 626-646. Berlin: Gruyter.

Pavlič, Matic. 2016. The word order parameter in Slovenian Sign Language transitive, ditransitive, classifier and locative constructions. PhD diss., Università Ca'Foscari Venezia.

Payne, Doris L., and Immanuel Barshi, eds. 1999. External possession. Amsterdam: Benjamins.

Pfau, Roland, Martin Salzmann, and Markus Steinbach. 2018. The syntax of sign language agreement: Common ingredients, but unusual recipe. Glossa: A Journal of General Linguistics 3(1): 1-46.

Ramchand, Gillian. 2008a. Verb meaning and the lexicon: A first phase syntax. Cambridge: Cambridge University Press.

Ramchand, Gillian. 2008b. Lexical items in complex predications: Selection as underassociation. Nordlyd $35(1)$.

Schembri, Adam. 2003. Rethinking "classifiers" in sign languages. In Perspectives on classifier constructions in sign languages, ed. Karen Emmorey, 3-34. New York: Lawrence Erlbaum.

Schlenker, Philippe. 2014. Iconic features. Natural Language Semantics 22(4): 299-356.

Sehyr, Zed Sevcikova, and Kearsey Cormier. 2015. Perceptual categorization of handling handshapes in British Sign Language. Language and Cognition 8(4): 501-532.

Supalla, Ted. 1982. Structure and acquisition of verbs of motion and location in American Sign Language. PhD diss., University of California, San Diego.

Talmy, Leonard. 2017. Foreword: Past, present, and future of motion research. In Motion and space across languages: Theory and applications, ed. Iraide Ibarretxe-Antuano, 1-11. Amsterdam: Benjamins.

Tenny, Carol. 1987. The aspectual interface hypothesis. In Lexical matters, eds. Ivan Sag, Anna Szabolcsi, 1-27. Stanford: CSLI Publications.

van Gijn, Ingeborg, and Inge Zwitserlood. 2006. Agreement phenomena in Sign Language of the Netherlands. In Arguments and agreement, eds. Peter Ackema, Patrick Brandt, Maaike Schoorlemmer, and Fred Weerman, 195-229. Oxford: Oxford University Press. 
Van Valin, Robert D. 2005. Exploring the syntax-semantics interface. Cambridge: Cambridge University Press.

Veenstra, Tonjes. 1996. Serial verbs in Saramaccan: Predication and creole genesis. The Hague: Holland Academic Graphics.

Wilbur, Ronnie B. 2008. Complex predicates involving events, time and aspect: Is this why sign languages look so similar? In Signs of the time: Selected papers from TISLR 2004, ed. Josep Quer, 217-250. Hamburg: Signum.

Wilbur, Ronnie B. 2010. The semantics-phonology interface. In Sign Languages, ed. Diane Brentari, 355380. Cambridge: Cambridge University Press.

Wood, Sandra. 1999. Semantic and syntactic aspects of negation in ASL, Master's thesis, Purdue University.

Zwitserlood, Inge. 2003. Classifying hand configurations in Nederlandse Gebarentaal. PhD diss., University of Leiden.

Zwitserlood, Inge. 2012. Classifiers. In Sign language: An international handbook, eds. Roland Pfau, Markus Steinbach, and Bencie Woll, 158-186. Berlin: de Gruyter.

Zwitserlood, Inge. 2017. Should the left hand know what the right hand is doing? Simultaneous classifier predicates in Sign Language of the Netherlands (NGT) as paratactic constructions. Ms., Radboud University, Nijmegen. 